\title{
Review
}

\section{VITAMIN K: THE NEW FACES OF AN OLD FRIEND - A ROLE IN BONE AND VASCULAR HEALTH}

\author{
Maria Zhelyazkova-Savova ${ }^{1 *}$, Silvia Gancheva ${ }^{1}$, Bistra Galunska ${ }^{2}$, and Daniela Gerova ${ }^{3}$ \\ ${ }^{1}$ Department of Preclinical and Clinical Pharmacology and Therapeutics, \\ ${ }^{2}$ Department of Biochemistry, Molecular Medicine and Nutrigenomics, \\ ${ }^{3}$ Department of Clinical Laboratory, Medical University, Varna, Bulgaria
}

\section{ABSTRACT}

There is an exciting research expansion on the novel roles of vitamin $K$ in the last decades. Subclinical deficiency in vitamin $K$ is believed to be widely spread, possibly contributing to age-related diseases. The present review is focused on the effects of vitamin $K$ on the skeleton and blood vessels, where it could be potentially useful in the prevention and treatment of osteoporosis and vascular calcification, both having a significant health impact in the society. The types (K1 and K2), nature and sources of vitamin $K$ are reviewed as well as the mechanisms of action underlying their effects. Gamma-glutamic carboxylation of several vitamin $K$ dependent proteins (VKDP), including clotting factors, is the primary mode of action of vitamin K, lead-ing to activation of proteins with specific functions. Priority was given to those VKDP that are involved in maintaining bone and vascular health. Other recently identified cellular transduction pathways through which vitamin $K$ acts are also outlined. Experimental in vivo data confirming the expected beneficial effects of vitamin $K$ on bones and blood vessels have paved the way for clinical studies. So far, the evidence from clinical experience with vitamin $K$ supplementation is promising, but still insufficient to recommend routine use of vitamin $K$ as a preventive agent. Several prospective randomized controlled clinical studies currently in progress are expected to give more clear-cut results allowing the routine use of vitamin $K$ as a reliable, cheap and safe medication in the prevention of bone loss and vascular calcification. Biomed Rev 2017; 28: 70-90

Keywords: vitamin K, osteocalcin, matrix Gla-protein, osteoporosis, vascular calcification

\section{INTRODUCTION}

In the last decades there is an exciting revival of interest for the pleiotropic effects of micronutrients. Examples include vitamin D and vitamin B12, for which a bulk of evidence has accumulated about their new roles and functions in health and disease. This interest in general has been triggered by the recognition that modern pattern of life and nutrition is associated with widespread subclinical deficiency of vitamins and minerals impacting significantly health quality. Multiple data point to the possibility that many of the chronic degenerative diseases of the civilized world could have been brought about by inadequate dietary intake of micronutrients. According to the "Triage theory" postulated by Ames (1), during periods of shortage, the functions of micronutrients that are required for short-term survival take precedence over those that are less essential. Thus, although frank deficiencies with vital conse-

\footnotetext{
Received 25 November 2017, accepted 6 December 2017

* Correspondence and reprint request to: Dr Maria Zhelyazkova-Savova, Department of Preclinical and Clinical Pharmacology and Therapeutics, Medical University, Varna, Bulgaria

E-mail: zhelyazkova@mu-varna.bg
} 
quences could be avoided with relatively low supplies, longterm inadequacy can potentially lead to age-related diseases. This is also true for vitamin K. Here we aim to review some of the expanding knowledge on newly identified effects and mechanisms of vitamin $\mathrm{K}$ that appear to have as yet unutilized therapeutic potential in many clinical conditions, especially affecting bone and cardiovascular (CV) system.

\section{HISTORY AND NATURE OF VITAMIN K}

Widely known today as anti-hemorrhagic factor, vitamin $\mathrm{K}$ was originally discovered by the Danish biochemist and physiologist Henrik Dam in 1929 during his studies on chickens fed cholesterol-free diet. He found that the lack of a lipidsoluble factor was associated with bleeding and later identified it as a koagulations vitamin (hence vitamin K) present in green leafs. The American biochemist Edward Doisy later isolated vitamin $\mathrm{K}$ from alfalfa independently from Dam and differentiated the two vitamers - K1 and K2. Henrik Dam and Edward Doisy shared the Nobel Prize for physiology or medicine in 1943 for their work on vitamin K.

The term vitamin $\mathrm{K}$ comprises two main types of chemically similar naphthoquinone compounds. Vitamin K1 (phylloquinone or phytomenadione, also phytonadione) is a 3-phythyl derivative of 2-methyl-1,4-naphtho-quinone structure (Fig. 1). It is mainly found in green leafy vegetables. In plants, vitamin $\mathrm{K} 1$ is functionally involved in photosynthesis where it acts as an electron acceptor. Foods rich in vitamin K1 are asparagus, Brussels sprouts, spinach, green beans, chard, broccoli, kale, mustard greens, parsley, sauerkraut, etc. Over $90 \%$ of the vitamin stores in the body come from plant sources.

Vitamin $\mathrm{K} 2$ is a collective name for a number of menaqinones - a family of related compounds where chains of repeated isoprenoid residues of different length are attached to position 3 of the naphtho-quinone structure (Fig. 1). Menaquinones are therefore denoted as MK-n, where "n" reflects the number of isoprenoid residues - from 3 to 11 . Depending on the number, menaquinones are subdivided into short-chain (biologically the most important example being MK-4, also menatetrenone) and long chain (MK-7 being the one mostly investigated) derivatives.

Unlike vitamin $\mathrm{K} 1$, menaquinones are mainly found in foods of animal origin, but in a significantly lower quantity. MK-7 is relatively high in cheese and butter, but it is particularly abundant in the typical Japanese dish of fermented soybeans dubbed natto. Bacterial flora in the gut (particularly Bacteroides) are capable of synthesizing long-chain menaqui-
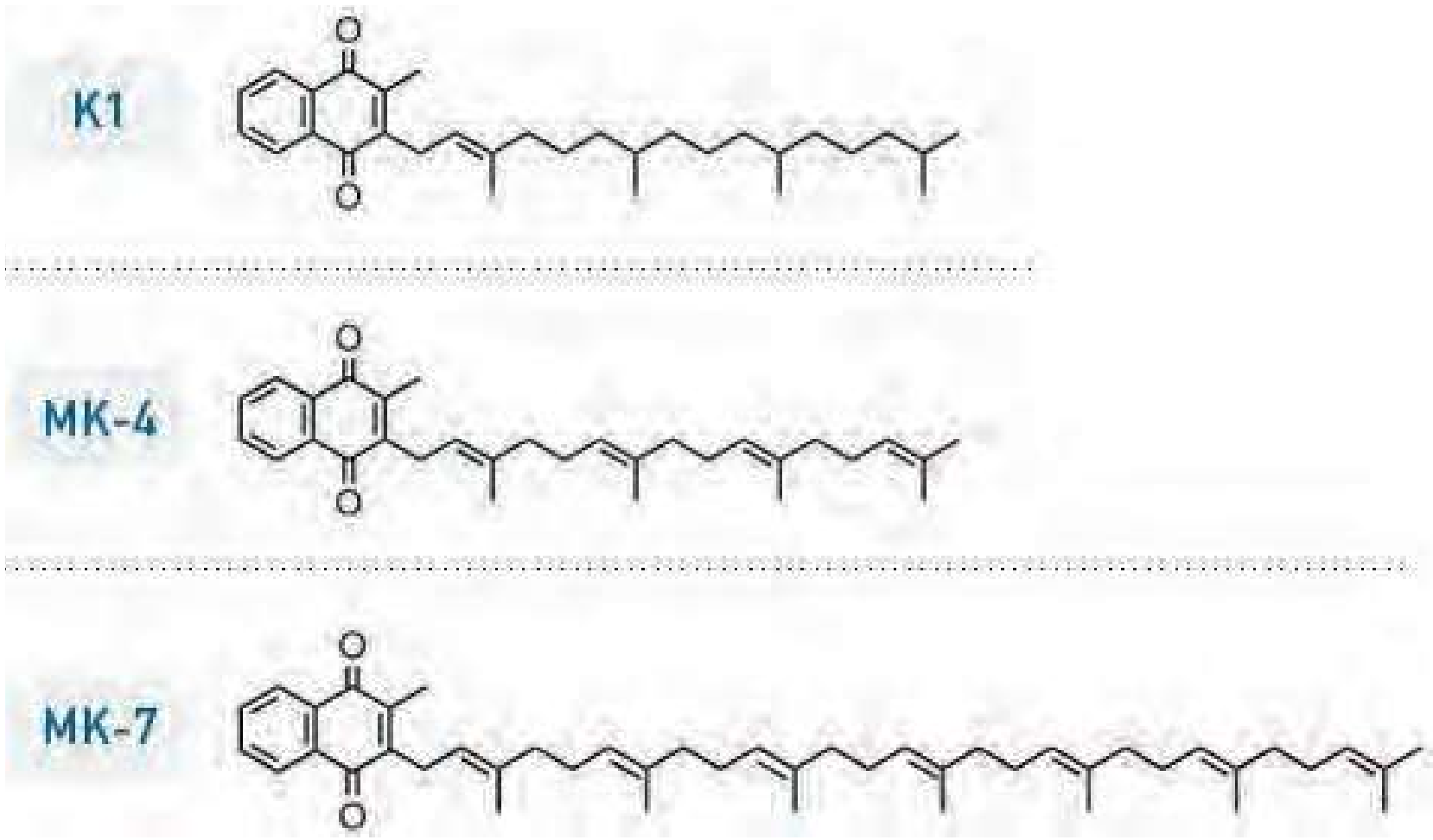

Figure 1. Chemical structure of $K$ vitamins. 
nones $(\mathrm{MK} \geq 7)$. It was once considered that intestinal bacteria are the main source of vitamin $\mathrm{K} 2$ for the body, but currently the colonic contribution for the menaquionone stores in the body is being questioned. It is now clear that the systemic absorption from the large intestine is problematic not only due to lack of bile acids, but also because of the presence of vitamin $\mathrm{K}$ in bacterial membranes, from where it is not readily available for absorption (2).

As for MK-4, which has important physiological implications - this form of vitamin $\mathrm{K} 2$ is not generally found in food. It is assumed, that the stores of MK-4 in the body are replenished by the conversion of vitamin $\mathrm{K} 1$ into menatetrenone, which occurs both in and outside the gastrointestinal tract (GIT) (3).

A third congener, vitamin K3 (menadione), is a synthetic pro-vitamin, which is converted to vitamin $\mathrm{K} 2$ in the gut. Its clinical use is limited due to toxicity.

\section{PHARMACOKINETICS OF VITAMIN K}

The two $\mathrm{K}$ vitamers differ significantly in their pharmacokinetics, while sharing similar mechanism of action in general. The differences in their tissues distribution partly explain their relatively specific involvement in different physiological functions. Absorption of vitamin $\mathrm{K}$ from nutritional sources occurs in the GIT. The presence of bile acids is essential for the intestinal absorption of dietary vitamin $\mathrm{K}$. It is assembled in chylomicrons together with dietary lipids and subsequently transported to the liver via chylomicron remnants (CR), with MK-7 being also incorporated in LDL. The delivery of dietary vitamin $\mathrm{K}$ to the bone is assumed to occur within CRs via receptor mediated endocytosis by LDL receptor-related protein and LDL-receptor expressed on osteoblasts (4). Apolipoprotein E (Apo E) as a constituent of CR appears to be an important determinant of tissue distribution of vitamin $\mathrm{K}$. The Apo E polymorphic variants promote CR clearance from circulation with very different efficiency, in the order $\mathrm{E} 2>\mathrm{E} 3>\mathrm{E} 4$, thus producing variable vitamin $\mathrm{K}$ plasma concentrations and tissue availability (5).

When comparatively tested for their bioavailability after oral intake, vitamin $\mathrm{K} 1$ produced a relatively lower peak after a single dose compared to MK-7. In addition, phylloquinone was more efficiently cleared from the blood than MK-7, the decline of which was considerably slower (6). Similarly, when administered on a long-term basis (40 days), the concentration of MK-7 was some 5 times higher compared to $\mathrm{K} 1$. These results show that MK-7 is better absorbed and has a significantly longer plasma half-life, allowing accumulation with chronic dietary intake or supplementation.

Vitamin $\mathrm{K}$ is distributed throughout the body with highest concentrations found in liver and pancreas. The hepatic pool is the major one in the human body and comprises K1 and longer chain $\mathrm{K} 2$ vitamers. MK-4, on the other hand, prevails in extrahepatic tissues, exceeding $\mathrm{K} 1$ concentrations in many tissues, particularly in brain and kidneys (7). The pattern of distribution may, however, differ in different species and dietary intakes (8).

The metabolism of vitamin $\mathrm{K}$, though poorly understood, is thought to involve both reactions from phase I (initial $\omega$-oxidation and subsequent $\beta$-oxidation in the side chain via the CYP family) and phase II (glucuronidation), leading to the production of water soluble metabolites excreted with urine, where they can be measured as an index of vitamin $\mathrm{K}$ status (9).

\section{CONVERSION OF VITAMIN K1 TO MK-4 IN HUMANS}

Dietary sources are low in MK-4. Still, MK-4 is present in body tissues in sufficient amounts. Conversion of $\mathrm{K} 1$ to MK-4 has been well-known in bacterial cells, but only recently was shown to be possible also in eukaryotes. Such a conversion was demonstrated in mice following oral or enteral, but not parenteral or cerebroventricular administration of phylloquinone (8). The biosynthesis of MK-4 in humans has been recently shown to depend on UBIAD1 (UbiA prenyltransferase domain-containing protein 1) - an enzyme with previously unknown functions (10). According to the working hypothesis of the authors (3), the phytyl side chain of phylloquinone is cleaved in the intestine and the intermediate metabolite menadione, after being delivered into the blood via the mesenteric lymphatics and transported to peripheral tissues, is prenylated to MK-4 by UBIAD1 (Fig.2).

\section{MECHANISMS OF ACTION OF VITAMIN K}

Vitamin $\mathrm{K}$ is well characterized as a co-factor of gamma glutamyl carboxylase (GGCX) - an enzyme essential for the post-translational modification of proteins by converting their glutamic acid (Glu) residues into gamma-carboxy glutamic acid (Gla) residues. The property that Gla-proteins have in common is their high affinity to calcium. This mechanism of action was unknown up until the early 1970s (some 40 years after the discovery of phylloquinone), when in a series of papers the Swedish chemist Stenflo reported that biosynthesis of prothrombin requires vitamin $\mathrm{K}$, that dicoumarol leads to 


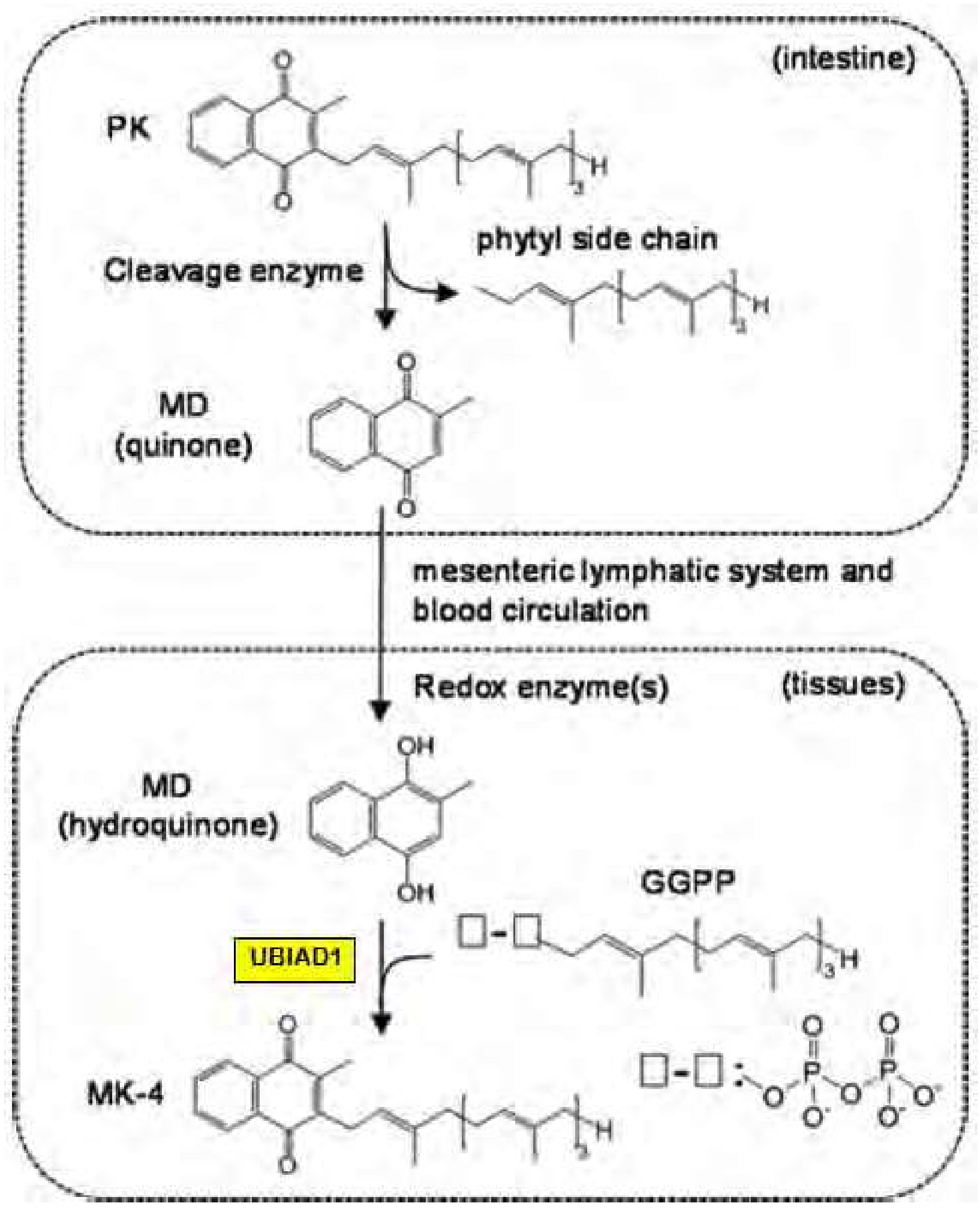

Figure 2. In vivo conversion of phylloquinone to MK-4. From (3). 


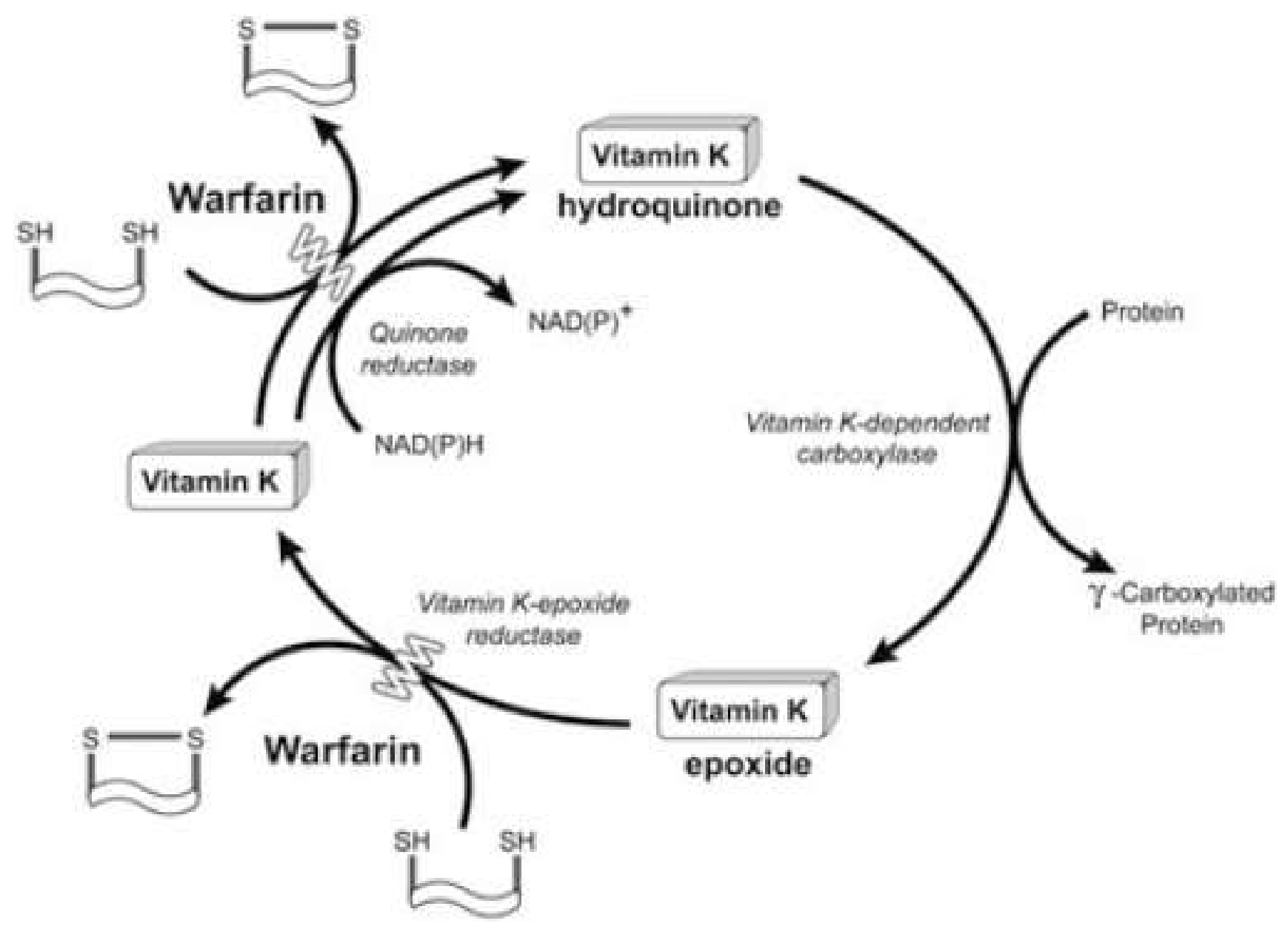

Figure 3. The vitamin $K$ cycle.

the synthesis of abnormal prothrombin unable to bind calcium and that carboxylation of the first 10 glutamic acid residues in prothrombin constitutes the vitamin K-dependent modification of prothrombin (11).

Currently, the gamma-glutamyl carboxylation is the classical mechanism of action recognized for vitamin $\mathrm{K}$, whereby it modifies not only coagulation factors II, VII, IX and X and the endogenous anticoagulant proteins $\mathrm{C}, \mathrm{S}$ and $\mathrm{Z}$ in the liver, but also a number of newly identified extrahepatic vitamin $\mathrm{K}$ dependent proteins (VKDP).

The process of gamma-glutamyl carboxylation involves the vitamin K cycle (Fig. 3) where the diet-derived vitamin in the form of quinone is reduced to its active form hydroquinone (KH2) by the quinone reductase. The KH2 is required by GGCX, which converts the uncarboxylated (uc) VKDP (or the glu-proteins) into gamma-glutamyl carboxylated proteins (Gla-proteins). In this reaction vitamin $\mathrm{K}$ is oxidized to epoxide, which is restored to its original form by the vitamin
K-epoxide reductase (VKOR). The continuous recycling of vitamin $\mathrm{K}$ allows that its essential functions be served with relatively low dietary intake. The enzymes responsible for the reduction of vitamin $\mathrm{K}$ are inhibited by the anticoagulant drugs like warfarin, widely known as vitamin $\mathrm{K}$ antagonists.

The currently known VKDP not involved in coagulation include osteocalcin, matrix gla-protein, Gas6 (growth arrest specific gene 6 protein), periostin and periostin-like factor, Gla-rich protein, etc. They have specific tissue distribution related to their putative functions. The best studied among these are osteocalcin and matrix Gla-protein in respect to their role in bone and CV health, respectively.

There are, however, gamma-glutamyl carboxylation independent mechanisms identified, including transcription modulation, regulation of sphingolipid metabolism, antioxidant and anti-inflammatory actions, etc. Through these multiple pathways vitamin $\mathrm{K}$ has been found to produce a variety of effects, unknown in the past. 
What are the potentiallynew physiological functions of vitamin $\mathrm{K}$ that have recently emerged? Vitamin $\mathrm{K}$ is thought to play a role in bone health, vascular calcification, brain function, cancer, energy metabo-lism, cellular growth, survival and signaling.

\section{VITAMIN K AND BONE HEALTH}

The discovery of osteocalcin (OC) as a bone specific VKDP - bone Gla protein (BGP) with a high affinity to hydroxyapatite triggered research aiming to determine the role of vitamin $\mathrm{K}$ in the skeleton. Since OC is the most abundant non-collagenous protein in bone, secreted by osteoblasts, it has long been con-sidered an indicator for bone formation. The exact function of $\mathrm{OC}$ in bone, however, remains obscure. The carboxylated form of OC is sensitive to vitamin $\mathrm{K}$ intake, being dependent on it for the gamma-carboxylaton of the three glutamic acid residues in its molecule. The inadequately carboxylated form of OC (undercarboxylated $\mathrm{OC}=\mathrm{ucOC}$ ) is thus considered a marker of a relative vitamin $\mathrm{K}$ deficiency. Levels of ucOC in-crease with age and have been found elevated in osteoporosis, reflecting changes in bone matrix associated with increased fragility (12).

\section{Preclinical studies}

Experimental studies have been performed in different ani-mal models to test the effects of vitamin $\mathrm{K}$ on bone in vivo. Bone changes in ovariectomized (OVX) rats reflect the mechanisms of postmenopausal osteoporosis and this is the experimental model most commonly utilized to study effects of drugs. Dietary intake or treatment with different $\mathrm{K}$ vitamers have demonstrated favorable skeletal results in general. MK-4 significantly increased trabecular $\mathrm{b}$ one volume (13), improved the impaired calcium balance (14), attenuated the decline in bone mineral density (15). Menatetrenone has also been shown to synergize with other anti-osteoporotic drugs like estrogens (15), raloxifene (16), teriparatide $(17,18)$. MK-7 was effective in preventing bone loss in OVX rats (19). However, in their comparative study with vitamin K1, MK-4 and MK-7, parallel to alendronate, Fu et al. (20) were unable to confirm the positive results reported earlier for vitamin $\mathrm{K}$ on ovariectomy-induced bone loss.

Testosterone deficiency- and immobilizationinduced osteopenia can be modeled in rats by orchidectomy (ORX) and sciatic neurectomy (NX), respectively. Chronic administration of vitamin $\mathrm{K} 2$ in OXR and NX rats resulted in suppression of bone resorption and stimulation of bone formation (21).

Vitamin $\mathrm{K}$ attenuated drug-induced osteoporosis. In rats chronically treated with prednisolone, the reduced bone mineral density was inhibited by MK-4 and at least partly this effect was considered due to enhanced bone formation as revealed by histomorphometric analysis (22). In a rat femoral osteotomy model with and without glucocorticoid (GC) treatment, vitamin K2 demonstrated a bone healing capacity in both groups (23). Phenytoin is an osteoporosis inducing drug with chronic administration. Although this complication is usually explained by induction of vitamin D metabolism, the reduced bone mineral density in rats treated with phenytoin was counteracted by menatetrenone and it was subsequently shown that phenytoin-induced bone loss was associated with reduced serum and bone levels of vitamin K2, suggesting also a role for vitamin $\mathrm{K}$ in this adverse effect $(24,25)$. Preclinical data, being strongly suggestive for beneficial effects of vita$\min \mathrm{K}$ on bone, predispose to clinical verification and are a good reason for clinical trials to be conducted to confirm its usefulness in maintaining bone health.

\section{Epidemiological and interventional clinical studies}

A number of epidemiological observations actually precede experimental studies and provide the earliest associations between vitamin $\mathrm{K}$ intake and improved bone health. Interventional trials have been undertaken to support the benefit of vitamin $\mathrm{K}$ in osteoporosis with clinical evidence. One of the first large epidemiological studies was the Nurses' Health Study, in which a large cohort of over 72 000 women was prospectively followed up for 10 years and demonstrated an inverse association between vitamin $\mathrm{K}$ consumption and osteoporotic fractures of the hip (26). Most of the positive hu-man results on bone health, especially for vitamin K2, come from Japan, where the traditional consumption of natto, high in MK-7, has been associated with lower incidence of hip fractures (27). An ecological study from Japan found a signif-icant negative correlation between vitamin $\mathrm{K}$ intake and hip fracture incidence both in men and women (28). Similar re-sults were found for vitamin $\mathrm{K} 1$ intake and risk of hip fracture in the Framingham cohort of elderly men and women (29) and in a 3 year follow up in elderly population of Norway (30).

Although osteoporotic fractures are thought to be the result of bone mineral loss, vitamin $\mathrm{K}$ intake failed to show effect on bone mineral density (MBD) in elderly participants in the Framingham heart study (29). Later on, some cross sectional studies provided evidence for a beneficial impact of high dietary vitamin K on BMD $(31,32)$, but negative results 
were also reported $(33,34)$. In elderly Japanese men, consumption of natto was associated with higher BMD and reduced levels of undercarboxylated osteocalcin (ucOC) (35).

A recent meta-analysis evaluating the controversial connection between dietary vitamin $\mathrm{K}$ intake and risk of fractures concluded that the present evidence supports a moderate decrease in fracture incidence when high intake of vitamin $\mathrm{K}$ has been followed for more than 10 years (36).

Supplementation studies, conducted to check the effects of vitamin $\mathrm{K}$ in osteoporosis, have yielded inconsistent results. Both vitamin K1 and K2 have been investigated. Generally the interventional trials all suffer the common fault of including a relatively small number of subjects. Menatetrenone, given in a dose of $45 \mathrm{mg} /$ day to 120 osteoporotic patients for 24 months, effectively prevented fractures and sustained BMD compared to the control group (37). This was accompanied by a significant reduction in the plasma levels of ucOC. Two other studies with MK-4 on postmenopausal osteoporosis for 2 years revealed a better effect on lumbar spine BMD when combining vitamin $\mathrm{K}$ with vitamin D3 compared to either treatment when given alone $(38,39)$. It was also shown, that, with the high doses of MK-4 used $(45 \mathrm{mg} / \mathrm{kg}$ daily), the coagulation parameters remained in the reference limits and no adverse effects were reported (39). The ECKO study in Canada followed a cohort of 440 postmenopausal women with osteopenia, administered vitamin K1 5 mg daily for 2-4 years, and found no protection against age-dependent decline in BMD, but reduced fracture incidence, suggesting that the effect of vitamin $\mathrm{K} 1$ on bone may not be mediated by BMD or bone turnover (40). In their study on 452 elderly men and women, treated with vitamin K1 500 mcg daily and recommended amounts of vitamin D and calcium for three years, Booth et al (41) found no additional benefit on bone health at the spine or hip, although the percent of ucOC was significantly lowered. In still another study, the reduction of plasma ucOC with vitamin K1 (1 mg daily) and MK-4 (45 mg daily) for 1 year was not associated with positive changes in bone density or geometry in 381 postmenopausal healthy North American women receiving also calcium and vitamin D (42). Negative findings were reported also by Inoue $e t$ al (43) and Emaus et al (44) who supplemented postmenopausal women with either $45 \mathrm{mg} / \mathrm{kg}$ of MK-4 or $360 \mathrm{mcg}$ of MK-7 in the form of natto capsules. However, in 173 postmenopausal women, the supplementation with small doses $(100 \mathrm{mcg})$ of vitamin K1 and vitamin K2 (MK-7) in dairy products, enriched in calcium and vitamin $\mathrm{D}$, for 12 months, resulted in a significant decrease of ucOC and an increase of the lumbar spine BMD (45). In addition, the group supplemented with vitamin K2 had also elevated levels of Insulin-like growth factor 1 (IGF-1), essential for the osteoblast differentiation. Lower daily doses of MK-4 $(1.5 \mathrm{mg} / \mathrm{kg})$ were also found effective in preventing bone mineral loss and reducing ucOC in healthy elderly women (46).

Several meta-analyses have been published to evaluate the clinical benefit of vitamin $\mathrm{K}$ in osteoporosis. Cockayne et al (47) analyzed 13 controlled randomized clinical trials using supplementation with vitamin $\mathrm{K} 1$ and $\mathrm{K} 2$ to adult participants for longer than 6 months and concluded that there is evidence for protective effect against bone loss, with MK-4 displaying a stronger effect in preventing fractures among Japanese patients. A recent review by Iwamoto (48) on the effect of monotherapy with MK-4 found evidence for positive effect on fracture incidence in postmenopausal women with osteoporosis. In Japan, MK-4 is officially approved for prevention and treatment of osteoporosis under the brand name Glakay of Eisai Co. However, summarizing the bulk of evidence from interventional studies published so far, Guralp and Erel (49) concluded that there were no sufficient data to support the routine recommendation for the use of vitamin $\mathrm{K}$ for osteoporosis prevention in healthy postmenopausal women.

\section{Do vitamin K antagonists affect bone?}

Another contradictory line of evidence is related to the effect of vitamin $\mathrm{K}$ antagonists, used widely as anticoagulants in clinical practice, on bone. Several studies have addressed the issue with conflicting results. Caraballo et al (50) conducted one of the earliest trials as a retrospective study on a large population-based cohort of women surviving a thromboembolic event and exposed to oral anticoagulants (6 314 person-years follow up for the period 1966-1990). The results showed that long-term exposure (for 12 months or more) to vitamin $\mathrm{K}$ antagonists was an independent predictor for the vertebral and rib fractures. A more recent study aiming to examine the association between long-term warfarin use and osteoporotic fractures in patients with atrial fibrillation, however, found no such association (51). Vitamin $\mathrm{K}$ antagonists are also widely used in children. A case control study looking at BMD in 17 long-term warfarin users (8.2 years on the average) found that the lumbar spine mineral density in exposed patients was significantly reduced compared to controls (52). Hemodialysis patients appear to be particularly susceptible to warfarin. In a cross-sectional study men receiving anticoagulation for at least 1 year had more vertebral fractures and 
significantly reduced total osteocalcin compared to non-treated male hemodialysis patients (53). It is also worth noting, that warfarin use during a specific vulnerable period of pregnancy $\left(6^{\text {th }}-9^{\text {th }}\right.$ week of gestation), may induce the "warfarin embryopathy", characterized, among others, by osteodystrophy, which is manifested by a nasal hypoplasia and stippled epiphyses. These skeletal malformations are thought to result from the inability of vitamin $\mathrm{K}$ to carboxylate osteocalcin and matrix Gla-protein, postulated to be critical for the embryonic cartilage and bone differentiation at least in part through modulation of calcium deposition (54).

\section{Is osteocalcin mediating the protective effects of vitamin $K$ on bone?}

Mechanisms, whereby vitamin $\mathrm{K}$ favorably affects bone, remain elusive. It was initially considered that these effects were related mainly to the gamma-glutamyl carboxylation of OC due to the high affinity of cOC to hydroxyapatite. However, experiments with OC knockout mice showed no evidence of bone loss, and the bones of OC-deficient mice were even thicker compared to the wild type littermates, suggesting an inhibitory effect of $\mathrm{OC}$ on bone formation without impairing bone resorption or mineralization (55). Interestingly, a similar phenotype of increased bone formation was described in mice made osteoblast-specific GGCX deficient, implying that gamma-glutamyl carboxylation is not the mechanism responsible for the bone-protective effect of vitamin K (56). Still, with the use of a more sensitive assay (Fourier transform infrared microspectroscopy) Boskey et al (57) demonstrated a role for $\mathrm{OC}$ in mineral maturation. More recently, it was discovered that $\mathrm{OC}$, by interacting with osteopontin, is involved in the formation of dilatational bands, critical for energy dissipation during bone fracture; therefore, by this mechanism $\mathrm{OC}$ is thought to determine fracture toughness of bone (58).

\section{Other VKDP in bone may also play a role}

Matrix Gla protein (MGP) has been originally identified in bone, but now it is clear that it is predominantly expressed in vascular smooth muscle cells and in chondrocytes. It is currently known as one of the potent inhibitors of calcification of arteries and cartilage (59). Mice lacking MGP died early in life due to hemorrhage from ruptured calcified aorta, but had also a phenotype of shorter stature and low bone mass. The bone loss in MGP deficient mice was rescued by inhibition of vascular calcification, providing evidence that arterial calcification affects bone remodeling (60).

Periostin (PO) is another VKDP with impact on bone.
It is highly expressed in the periosteum of long bones and in osteocytes, in addition to many other tissues. In the skeleton, it serves both as a structural molecule of bone matrix and as a signaling molecule to stimulate osteoblast function and bone formation. It is postulated to promote injury repair in bone and extra-skeletal tissues. Periostin null mice exhibited low mass and decreased strength of bone. The serum levels of PO in postmenopausal women with osteoporosis were found to predict fracture risk independently from BMD. Although PO belongs to the family of VKDP, it is not known at present whether gamma-glutamyl carboxylation is essential for its functions (61).

Periostin-like factor is also potentially involved in the effect of vitamin K. It is expressed in bone, heart and vascular smooth muscles. It appears to have a role in osteoblast differentiation, bone formation and in fracture healing (62).

\section{Non gamma-glutamyl carboxylation pathways}

Cellular mechanisms different from involvement of VKDP appear to be relevant to the effects on bone. A role of a transcription regulator for vitamin $\mathrm{K}$ has recently been described as an important aspect of its complex mode of action.

Among the novel mechanisms established, is the function of vitamin $\mathrm{K}$ as a ligand to the nuclear steroid and xenobiotic receptor (SXR). The latter was previously considered an orphan receptor. It was initially regarded exclusively as a xenobiotic biosensor in the liver. It is now known that SXR is expressed in bone and other tissues, it is critical for bone metabolism and is currently identified as a target for the ac-tion of vitamin $\mathrm{K}$ (63). By activating this transcription factor, vitamin $\mathrm{K} 2$ has been shown to increase mRNA levels for osteoblast markers like bone alkaline phosphatase, osteoprotegerin, osteopontin, and MGP in osteosarcoma cells. Bone markers were also induced in primary osteocytes isolated from wild-type murine calvaria, but not from cells deficient in the mouse ortholog of SXR, the pregnane xenobiotic receptor PXR. In subsequent studies it was demonstrated that vitamin $\mathrm{K} 2$ regulated the transcription of genes that encode extracellular matrix proteins via SXR activation, resulting in increased accumulation of collagen in osteoblastic cells. This SXR dependent pathway is thought to contribute to the improved quality of bone induced by vitamin K2 (64).

Atkins et al. (65) focused their research with vitamin K1, $\mathrm{K} 2$ and $\mathrm{K} 3$ on the differentiation and function of human primary osteoblasts. They established that all the vitamers tested were capable of promoting osteoblast-to-osteocyte transition, with osteocyte density and viability being considered deter- 


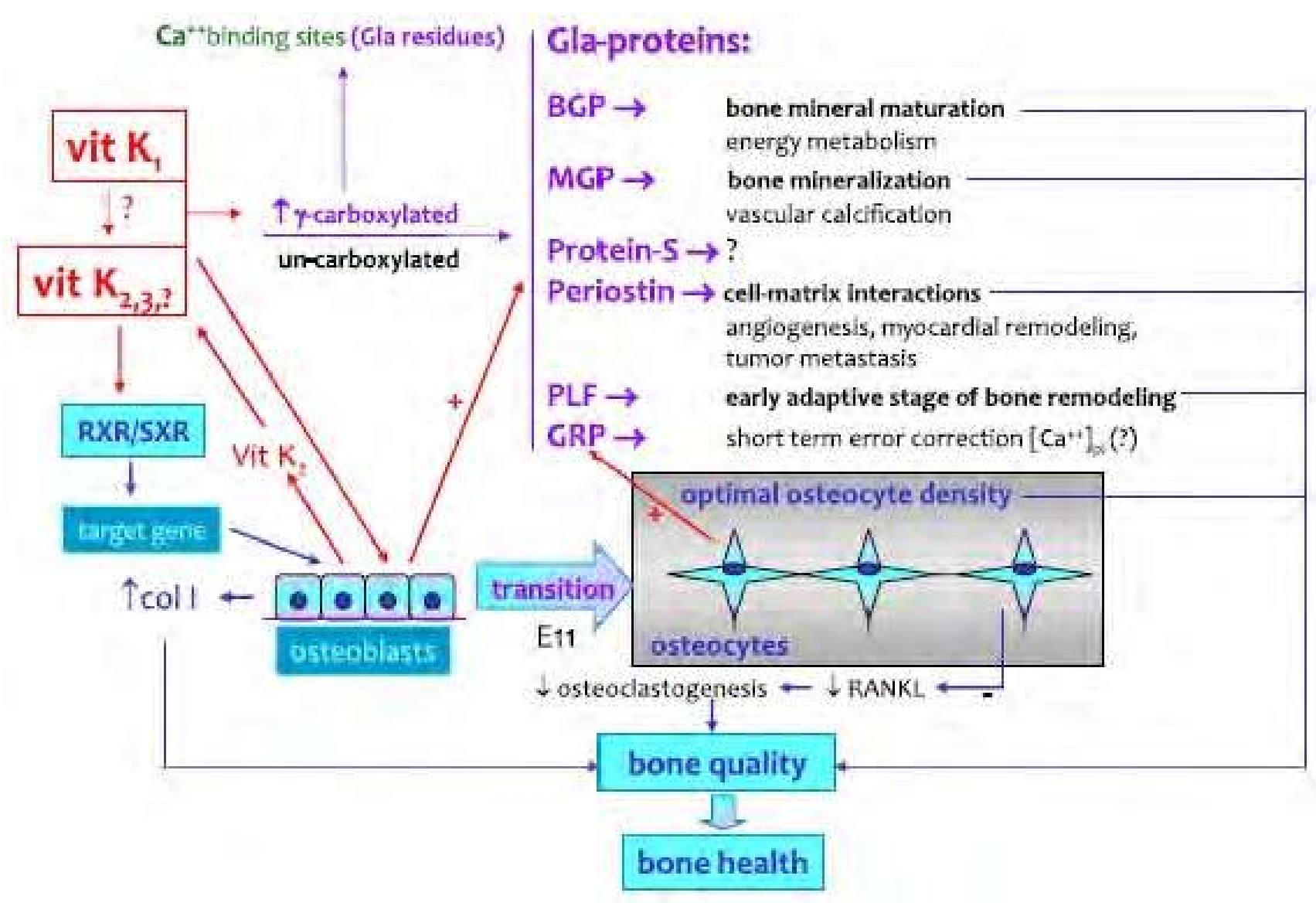

Figure 4. Simplified depiction of the pleiotropic function of vitamin $K$ in bone. Vitamin K acts by a tissue- and cell-specific carboxylation/decarboxylation process of Gla-proteins that are endowed of structural and regulatory functions in bone and in nonmineralized tissues and by a novel signaling pathway through a transcription factor, the steroid and xenobiotic receptor (SXR). The vitamin K's ability to promote collagen accumulation, cell-matrix interactions, matrix mineralization, mineral maturation, and osteocyte differentiation (all determining factors of bone quality) by gamma-carboxylation dependent and independent mechanisms might be relevant to bone health. From (69).

minants of optimal bone quality. At the same time vitamin $\mathrm{K}$ decreased the osteoclastogenic potential of these cells by lowering RANKL expression. Interestingly, K2 and K3 vitamers were more potent and their effects were less warfarinsensitive than those of K1, suggesting potentially genomic (GGCX-independent) underlying mechanisms.

Another signaling pathway, distinct from GGCX and SXR, has also been identified to mediate the transcription activity of vitamin K2. Novel target genes in osteoblasts growth differentiation factor 15 (GDF15) and stanniocalcin 2 (STC2), have been found up-regulated by MK-4 through enhanced phosphorylation of protein-kinase A (66). The action was specific for this particular $\mathrm{K}$ vitamer, considered to be the most active, probably due to its specific side chain.

It has been established that NF-kB signal transduction is critical for osteoclasts development, function and survival, while exerting inhibitory actions on osteoblasts, thus presenting opportunities for new therapeutic targeting (67). The effects of vitamin $\mathrm{K}$ on $N F-k B$ signaling pathways were investigated and the results revealed that by antagonizing basal and cytokine-induced activation of NF-kB, vitamin $\mathrm{K} 2$ produced a dual anabolic (in osteoblasts) and catabolic (in osteoclasts) action. This could, at least partly, explain the rare capacity of vitamin $\mathrm{K} 2$ to simultaneously increase bone formation and suppress bone resorption (68).

Overall, the mechanisms through which vitamin $\mathrm{K}$ affects bone homeostasis, are complex and comprise both involvement of VKDPs and variable GGCX-independent pathways, mainly related to its transcription activity (Fig.4). The majority of clinical and experimental evidence supports the 
higher activity of vitamin K2. In addition, the recent information points to shifting the focus of interest regarding vitamin $\mathrm{K}$ therapeutic potential in bone, from effects on bone quantity to effects on bone quality (69).

Although much remains to be elucidated from the mechanistic point of view, the accumulated clinical data, together with the expanding knowledge on how vitamin $\mathrm{K}$ works on bone, implies that it could become an important therapeutic tool in osteoporosis. However, prescribing recommendations should be based on confirmed efficacy in large prospective multi-center randomized controlled clinical trials that are still to be done or are currently in progress.

\section{VITAMIN K AND VASCULAR HEALTH}

Vascular calcification is an independent $\mathrm{CV}$ risk factor and a strong predictor of higher morbidity and mortality. It increases with age and dysmetabolic conditions. Patients with chronic kidney disease (CKD) and diabetes are particularly prone. For decades considered a passive and degenerative process, it is now clear that mineralization of vascular wall shares many biological features with the embryonic bone formation through osteochondrogenic differentiation of vascular smooth muscle cells (VSMC) under appropriate conditions. Modified VSMC express proteins typical for osteoblasts like osteocalcin, bone alkaline phosphatase, osteoprotegerin, and osteopontin. The main triggers for the initial transition of VSMC from a secretory (synthetic) to osteochondrogenic phenotype appear to be the hyperphosphatemia and hypercalcemia, which typically occur in end-stage CKD (70), but a number of additional factors, such as inflammation, oxidative stress, and metabolic disorders are able to accelerate the process (71). A key event in such a phenotypic modulation of VSMC is the release of mineralization-competent extracellular vesicles, capable of efficiently nucleating hydroxyapatite in the absence of inhibitors. The process goes on with further transformation of secretory VSMC into osteoblast-like cells with the help of bone morphogenetic protein 2 (BMP2). Osteochondrogenic VSMC are susceptible to apoptosis, they secrete more matrix vesicles and apoptotic bodies, resulting in extracellular mineralization and accelerated apoptosis (72). The active regulation of this process involves circulating (such as fetuin A) and local (in the vessel wall) calcification inhibitors.

\section{Matrix Gla-protein}

Among the local calcification inhibitors in the vascular wall a pivotal role is played by the matrix Gla-protein (MGP), ex- pressed in chondrocytes and vascular smooth muscle cells. It was the first calcification inhibitor discovered, initially identified in bovine bone (73). Its function of inhibiting arterial calcification was convincingly demonstrated with the generation of MGP null mice (59). The massive vascular calcification led to early death of the genetically modified animals due to aortic rupture. Subsequently, the calcification inhibiting activity of MGP was confirmed by Price et al (74), who used high dose warfarin to induce calcification in large arteries and aorta by inhibiting MGP gamma-glutamyl carboxylation and thus rendering it inactive. Importantly Schurgers et al (75) were able to demonstrate that warfarin-induced arterial medial elastocalcinosis in rats could be effectively reversed by vitamin $\mathrm{K}$ rich diet, reducing arterial calcium content by $50 \%$ and restoring the impaired arterial distensibility as a clinical parameter of vascular elasticity. Vitamin K1 and K2 had similar efficacy in this model, although it was expected that MK-4 would be more active based on previous research (76). It was hypothesized that with the high dose of vitamin K1 used, a significant amount of it has been converted to menatetrenone possibly contributing to the observed effect.

\section{What are the putative mechanisms whereby MGP exerts its inhibitory effect on vascular calcification?}

Much work has been dedicated to elucidate the mode of action of MGP and several mechanisms have been outlined. Matrix Gla-protein contains 5 glutamic acid residues that require vitamin K-dependent gamma-carboxylation. That post-translational modulation of MGP is essential for its anti-calcification activity was demonstrated by Schurgers et al (77), who observed accumulation of carboxylated MGP (cMGP) in healthy arteries, whilst in atherosclerotic vessels the undercarboxylated form (ucMGP) was present. They concluded that ucMGP is strongly associated with vascular calcification of different etiologies. This was confirmed clinically in patients with percutaneous coronary intervention who had lower serum levels of MGP compared to healthy controls. At present, ucMGP is recognized as a biomarker sensitive of detecting CV calcification (78). Because the only known function of Gla-residues is to bind calcium, it is plausible that the effect of MGP could be mediated, at least partly, through interference with calcium homeostasis. Indeed, it was Price et al (74) who first proposed the hypothesis according to which MGP binds tightly and selectively to hydroxyapatite crystal nuclei and prevents their growth and ability to seed daughter crystals. This idea was later confirmed and further developed by other authors (reviewed in 78). Gamma-glutamyl car- 


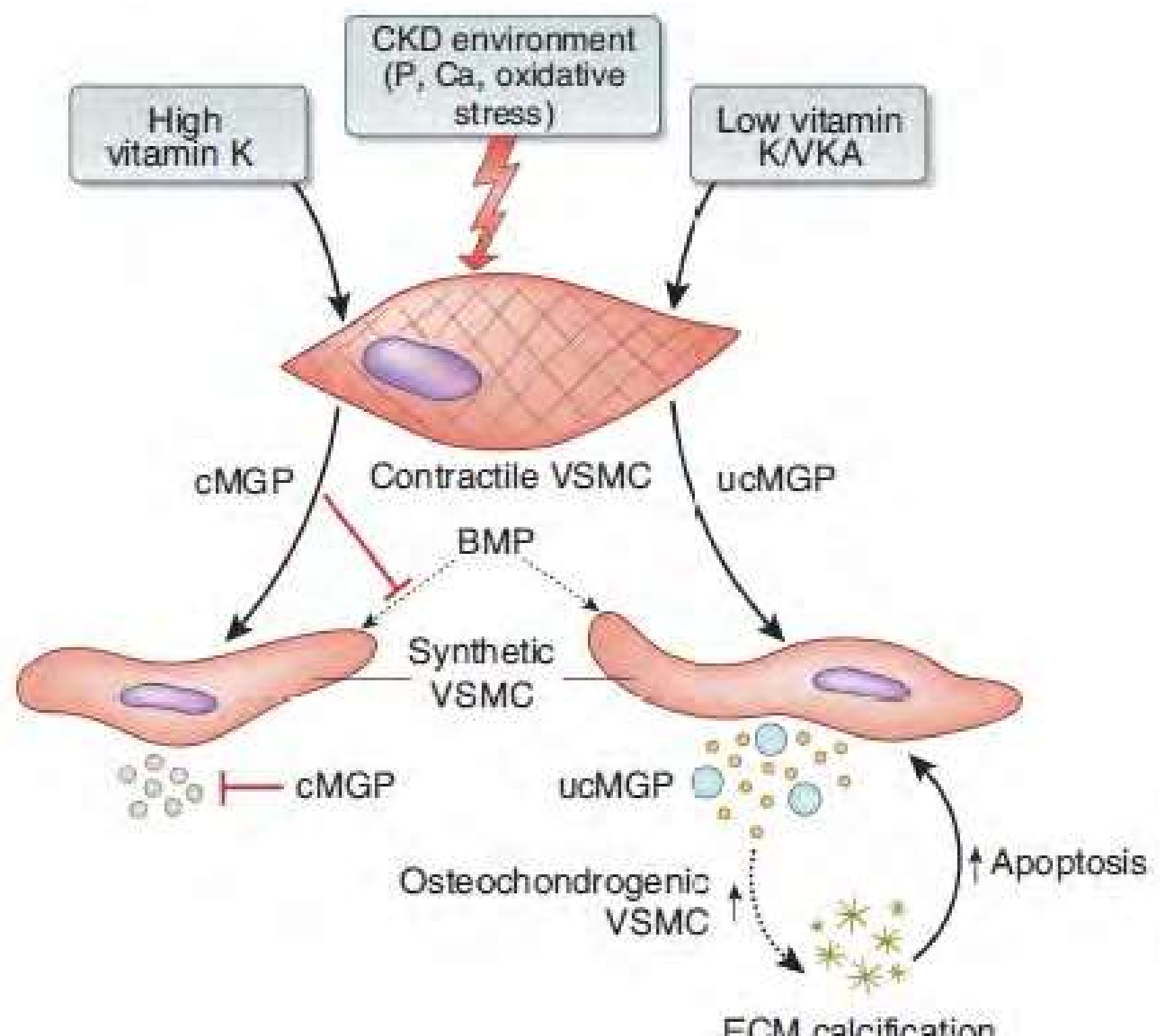

Figure 5. Vascular smooth muscle cells (VSMC) synthesize matrix Gla-protein (MGP), and in the presence of sufficient vitamin $K, M G P$ is produced in its carboxylated form and is thereby able to prevent mineralization. From (72).

boxylation is not the only posttranslational modification that MGP undergoes. It is also subjected to serine phosphorylation which has been found to contribute to its calcification inhibitory activity (79). Thus the inactive dephosphorylated and uncarboxylated MGP (dp-ucMGP) is currently considered a useful inverse marker of vitamin $\mathrm{K}$ status in the healthy population (80) and a reliable indicator of increased risk for vascular disease (81).

A second important molecular mechanism of MGP is related to its ability to antagonize the BMP2-induced os- teochondrogenic differentiation of VSMC. It was reported that MGP was able to bind and neutralize BMP2 with optimal conditions for this being the presence of calcium and Gla residues (82). Bostrom et al (83) provided direct in vitro evidence for the modulating activity of MGP on the osteoinductive properties of BMP2 by treating cells with different expression of MGP with BMP2.

Finally, a role for MGP as an anti-apoptotic factor is suggested. Apoptosis is an important step in vascular calcification. There is evidence pointing to both direct and BMP2- 
mediated inhibition of MGP on VSMC apoptosis (84). In his brilliant review on the role of vitamin $\mathrm{K}$ as a key regulator of vascular calcification in CKD, Schurgers (72) summarizes the process by the following graphic illustration (Fig. 5):

Other Gla proteins involved in vascular calci ication Matrix Gla-protein is not the only Gla-protein related to vas-cular calcification. Two other members of the VKDP fam-ily are associated with this process: Gla-rich protein (GRP) and Gas6, GRP being the latest Gla-protein identified. Its name reflects the largest number of glutamic acid residues contained (putative 15 residues in humans) and the highest density of Gla/protein size, indicating a significant potential for calcium binding. It was originally isolated from calcified cartilage of Adriatic sturgeon and subsequently identified in mammalian skeleton and soft tissues (85). The function of GRP has just recently been revealed. Knockout mice have been demonstrated to present no calcification anomalies, implying GRP is not essential for their normal development (86), while in zebra fish the deletion of GRP is associated with severe growth impairment and skeletal disorders - a phenotype closely mimicked by the condition induced by warfarin in the same species (87). GRP has been found accumulated in sites of ectopic calcification in rat and human skin, vascular and cartilaginous tissues (88). In an ex vivo model of human vessel culture it was shown that the carboxylated form of GRP was able to inhibit calcification to the same extent as MGP and fetuin-A. At least partly this effect can be explained by GRP binding to calcium thereby protecting VSMC from the $\mathrm{Ca} / \mathrm{P}$-induced shifting from a contractile to a secretory osteochondrocytogenic phenotype, similarly to the mechanism described for MGP. GRP was also found to be a part of MGP-fetuin-A protein complex at sites of valvular calcification, possibly representing a powerful an-timineralization system (89). Thus GPR has been established as a new vitamin $\mathrm{K}$ dependent player on the scene of vascular calcification with inhibitory functions and possible clinical implications (90).

Another VKDP relevant to calcification of blood vessels is Gas6. Gas6 displays a high structural homology with the natural anticoagulant protein $\mathrm{S}$, but has low serum levels and specific tissue expression, suggesting unique functions among the VKDPs. What distinguishes Gas6 is its mechanism of action that involves Gla-dependent interaction with tyrosine kinase receptors of the TAM family (Tyro3, Axl and MerTK) (91). TAM receptors function as homeostatic regulators in adult tissues and organ systems that are subject to continuous challenge and renewal throughout life, but are not active during embryonic development. They have prominent roles in mature immune, reproductive, hematopoietic, vascular, and nervous systems. Identified ligands for TAM receptors are Gas6 and Protein S, considered essential for the efficient phagocytosis of apoptotic cells and membranes in these tissues (92). In vascular calcification Gas6 is thought to be involved in the apoptotic modulation of VSMCs. It has been recently shown that vitamin K2 treatment of primary cultured VSMCs significantly inhibited $\mathrm{CaCl} 2$ - and b-sodium glycerophosphate-induced calcification and cell apoptosis, which was dependent on restored Gas6 expression and activated downstream signaling by Axl, p-Akt, and Bcl2. Addition of exogenous rmGas6 enhanced the beneficial effects of VK2 and VSMC apoptosis was further reduced. These results indicate that Gas6 is critical in VK2-mediated attenuation of VSMC calcification by blocking apoptosis (93).

Important practical questions that arise behind this basic research, are whether dietary status of vitamin $\mathrm{K}$ is related to vascular calcification, whether vitamin $\mathrm{K}$ intake or supplementation could be expected to confer $\mathrm{CV}$ protection and whether there is a risk of vascular calcification associated with long-term use of vitamin $\mathrm{K}$ antagonists.

\section{Clinical trials}

Epidemiological studies or cross sectional observations have addressed the issue of potential CV benefits of $\mathrm{v}$ itamin $\mathrm{K}$. Inverse associations have been found between dietary vitamin $\mathrm{K}$ intake or markers of vitamin $\mathrm{K}$ status and different $\mathrm{CV}$ outcomes.

In one of the first observational studies, the Rotterdam study, a large cohort of more than 4000 subjects aged 55+ were tracked for seven years and the consumption of vitamin $\mathrm{K} 2$, but not K1, was found to be related to reduced aortic calcification and CV and all-cause mortality (94). The early clinical data as summarized by Shea and Holden (95) suggested that dietary intake of menaquinone might be more active as calcification protector, but the only study with vitamin K1 supplementation showed that phylloquinone was able to slow the progression of coronary calcification as well (96). These results were not convincingly confirmed when direct serum phylloquinone was measured, as its low level was associated with extreme coronary calcification progression in hypertensive patients in one study (97), but in another study it was not associated with vascular calcification (98).

Several studies have related coronary and peripheral artery calcification and CV outcomes to the plasma levels of 
dp-ucMGP as an inverse marker of vitamin $\mathrm{K}$ status, but the results are inconclusive. In healthy postmenopausal women a borderline significant association was found between dp-ucMGP and coronary artery calcification (99), while in a similar population of another study the levels of this marker were not associated with CV and stroke risk (98).

Arterial calcification is implicated in loss of vascular elasticity (100), therefore arterial stiffness has also been examined in relation to vitamin $\mathrm{K}$ status. Aortic and carotidfemoral pulse wave velocity was found to be positively associated with dp-ucMGP in general adult populations (101, $102)$, as well as in diabetic patients (103). Vascular calcification is recognized as a significant CV risk. Van den Heuvel et al (81) observed a more than 2-fold significantly higher risk of $\mathrm{CV}$ disease for the highest tertile of dp-ucMGP as compared with the lowest tertile among community-dwelling older men and women. In patients with overt vascular disease, circulating dp-ucMGP and dp-cMGP were independently associated with the risk of all-cause and CV mortality (104).

Patients with $C K D$ are particularly vulnerable to vascular calcification. In addition to the specific uremia-related risk factors, they commonly exhibit profound vitamin $\mathrm{K}$ deficiency. Holden et al (105) have shown that subclinical vitamin K (along with vitamin $\mathrm{D}$ ) deficiency is prevalent among patients with CKD. A cross-sectional study in postmenopausal women also revealed sub-optimal vitamin $\mathrm{K}$ status as assessed by significantly elevated plasma ucOC levels in hemodialysis patients compared to healthy controls (106). The insufficiency of vitamin $\mathrm{K}$ in kidney transplant recipients was an independent risk factor for increased mortality (107). Studies exploring the connection between vitamin $\mathrm{K}$ status and vascular calcification in renal patients have yielded inconsistent results $(108,109)$, but vitamin K2 supplementation in hemodialysis patients was demonstrated to markedly decrease the inactive MGP, providing the rationale for intervention trials aiming at vascular calcification inhibition (110).

All these studies in different populations confirm the notion that the subclinical vitamin $\mathrm{K}$ deficiency is related to higher $\mathrm{CV}$ risk and reveal the need of conducting vitamin $\mathrm{K}$ interventional trials, very scarce at present. One such study examined the effect of vitamin $\mathrm{K}$ supplementation on arterial stiffness as a measure of mechanical arterial properties, in healthy post-menopausal women. A significant decrease in arterial stiffness was found after 3 years of supplementation with MK-7 versus placebo group (111). Another small study aimed to assess the impact of vitamin K2 supplementation (MK-7) plus vitamin D for 3 months on the progression of atherosclerosis and vascular calcification in patients with CKD stage III-V. While the carotid intima-media thickness was reduced, no effect was seen on the coronary calcification score, however, there was a significant correlation between the indices of atherosclerosis and vascular calcification (112).

Vitamin $K$ antagonists and risk of vascular calcification Vitamin $\mathrm{K}$ antagonists are widely used drugs with established clinical benefits in treating and preventing thromboembolic disease. The major risk being bleeding, recently also concerns related to vascular calcification have arisen as a result of the increasingly recognized role of vitamin $\mathrm{K}$ as a calcification inhibitor. The first clinical results supporting a connection between the coumarin anticoagulant use and calcification was a small study by Schurgers et al. (113), in which they demonstrated aortic valve calcifications twice as severe in anticoagulated compared to untreated patients undergoing valve replacement. Koos et al. also found a higher coronary calcium content, as measured by multislice spiral computed tomography, in patients on oral anticoagulants versus patients without anticoagulants (114). These findings on coronary calcification were further corroborated in low risk patients with atrial fibrillation (115) and in patients with coronary artery disease (116). Other sites of vascular calcification femoral arteries (117), breast arteries (118), peripheral arteries of the lower limb (119) were also more commonly found in warfarin users. Atypical non-uremic calciphylaxis (cutaneous ischemia and necrosis caused by mural calcification of small and medium-sized blood vessels) has been described in patients on vitamin K antagonists (120). Coumarin anticoagulants have also been associated with non-vascular, e.g., tracheobronchial calcification (121). Patients with CKD are even more sensitive to vitamin $\mathrm{K}$ antagonists, due to the common vitamin $\mathrm{K}$ deficiency in this population. In a retrospective study, Holden et al (122) found that the severity of aortic valve calcification in hemodialysis patients was related to lifetime months of warfarin exposure. An observational cohort study in hemodialysis patients demonstrated that the group treated with acenocoumarol had higher concentrations of dp-ucMGP, which significantly correlated with the vascular calcification score (123). MK-7 given to patients on hemodialysis for 6 weeks was able to correct dose dependently the elevated circulating dp-ucMGP (110), but the arterial calcification was not assessed in this study. Whether or not improved vitamin $\mathrm{K}$ status translates into a reduction in vascular calcification is still unknown and clinical trials are in progress to elucidate this. The novel oral anticoagulants (NOACs), which spare vitamin K, should 
be potentially free from ectopic mineralization complications, but the prevailing renal clearance of these drugs is a disadvantage. Their dose should be reduced in patients with moderate reduction of renal function and due to lack of data, NOACs should be avoided in patients on hemodialysis (124).

\section{The "Calcium paradox" - a syndrome of vitamin K sub- clinical deficiency?}

Osteoporosis and $\mathrm{CV}$ diseases are common conditions of the advanced age leading to increased morbidity and mortality. Traditionally, these two diseases were considered independent and their association was underestimated. In the last decades, accumulating evidence indicates a close relationship between vascular calcification and bone disorders. A number of common pathophysiological mechanisms and interacting factors underlying both conditions have been identified, leading to the development of the "bone-vascular cross-talk" concept $(125,126)$.

Ectopic calcification in blood vessels is often accompanied by either decreased bone mineral density or disturbed bone turnover. Such associations were observed in the general population, but mostly in patients with osteoporosis and in those with CKD (127). The "Calcium paradox" thus implies loss of calcium from bones, making them brittle, and excess of calcium in arteries, making them rigid. One possible common cause could be the relative deficiency of vitamin $\mathrm{K}$ that develops with healthy aging and is accelerated by disease. Vitamin $\mathrm{K}$ is needed for the carboxylation of the bone Glaprotein osteocalcin, as well as of other VKDPs outlined earlier. In addition, gamma-glutamyl carboxylation independent mechanisms have been revealed as essential for the beneficial effects of vitamin $\mathrm{K}$ on the skeleton. On the other hand, through the activation of MGP, the central local vascular calcification inhibitor, but also of GRP, acting as a calcium regulator and a back-up of MGP for inhibition of ectopic calcification, and of Gas6 as an apoptotic modulator, vitamin $\mathrm{K}$ is able to prevent calcium accumulation in arteries (128).

One of the first clinical trials to support the "calcium paradox" hypothesis was a research published in 2007. In a 5-year placebo controlled randomized follow-up of a large cohort of healthy postmenopausal women, primarily designed to assess the impact of calcium on bone mineral density and fracture incidence, an upward trend in CV event rates was found in the group supplemented with calcium (129). Interestingly, among the possible mechanisms discussed, no mention was made about vitamin $\mathrm{K}$, and the question of how to balance between the detrimental effect of calcium on blood vessels and its potential benefit on bones was asked as yet unanswered.

In the light of the discussed mechanisms and available preclinical and clinical data on vitamin $\mathrm{K}$, it appears that the two aspects of the "calcium paradox" - osteoporosis and vascular calcification, could have a potentially common preventive therapy. However, the available clinical information is still inconclusive and does not allow routine prescription of vitamin $\mathrm{K}$. The new roles of vitamin $\mathrm{K}$ as an activator of important regulatory proteins for bone and $\mathrm{CV}$ health raises the necessity of conducting large-scale follow-up interventional clinical studies, not only in pathological conditions, but also in healthy populations at risk.

\section{Ongoing clinical trials}

In response to the published preclinical and epidemiological data and the recognized need for more reliable information, researchers were prompted to undergo clinical investigations with vitamin $\mathrm{K}$ supplementation to assess its vascular and/ or bone effects. Several on-going prospective controlled randomized clinical trials are currently looking to prove and confirm the benefits of both forms of vitamin K. The study populations include hemodialysis or CV patients in whom the progression of established arterial calcification will be followed; subjects with poor vitamin $\mathrm{K}$ status where the vascular stiffness will be evaluated, postmenopausal women with osteopenia in whom changes in bone mineral density and arterial stiffness will be examined, and also metabolic parameters will be assessed. Other trials, evaluating the effect of vitamin $\mathrm{K}$ antagonists in renal patients - with endstage renal disease or on hemodialysis, are also in progress, including comparative studies with factor $\mathrm{X}$ direct inhibitors (130).

The results of these ongoing trials will demonstrate whether and to what extent vitamin $\mathrm{K}$ supplementation is effective in the prevention of $\mathrm{CV}$ calcification or bone loss in patients at risk and with preexisting diseases (131).

\section{CONCLUSION}

Subclinical vitamin K deficiency has recently been recognized as an important factor in the development of vascular calcification and osteoporosis. Biologically plausible mechanisms of the effects of vitamin $\mathrm{K}$ on $\mathrm{CV}$ and bone disease have been elucidated and described. This makes the dietary intake or the supplementation a potentially effective and promising tool in the control of these conditions. Large studies and solid clinical evidence regarding vitamin K efficacy 
are awaited to confirm the positive results and to allow specific recommendations to be made for the preventive use of vitamin $\mathrm{K}$ as a relatively cheap and safe medication.

\section{CONFLICT OF INTEREST STATEMENT}

The authors certify that they have no affiliations with or involvement in any organization with any financial interest in the subject matter discussed in this review article.

\section{REFERENCES}

1. Ames BN. Low micronutrient intake may accelerate the degenerative diseases of aging through allocation of scarce micronutrients by triage. Proc Natl Acad Sci USA 2006; 103(47): 17589-17594. DOI: 10.1073/ pnas.0608757103.

2. Beulens JWJ, Booth SL, van den Heuvel EG, Stoecklin E, Baka A, Vermeer C. The role of menaquinones (vitamin K2) in human health. Br J Nutr 2013; 110: 13571368. DOI: 10.1017/S0007114513001013.

3. Hirota Y, Tsugawa N, Nakagawa K, Suhara Y, Tanaka $\mathrm{K}$, Uchino $\mathrm{Y}$, et al. Menadione (Vitamin K3) is a catabolic product of oral phylloquinone (Vitamin K1) in the intestine and a circulating precursor of tissue menaquinone-4 (Vitamin K2) in rats. J Biol Chem 2013; 288(46): 33071-33080. DOI: 10.1074/jbc.M113.477356.

4. Shearer MJ, Fu X, Booth SL. Vitamin K, nutrition, metabolism, and requirments: Current concepts and future research. Adv Nutr 2012; 3: 182-195. DOI: 10.3945/ an.111.001800.

5. Kohlmeier M, Salomon A, Saupe J, Shearer MJ. Transport of vitamin K to bone in humans. J Nutr 1996; 126(4): 1192S-1196S.

6. Schurgers LJ, Teunissen KJ, Hamulyak K, Knapen MH, Vik H, Vermeer C. Vitamin K-containing diet supplements: comparison of synthetic vitamin $\mathrm{K} 1$ and nattoderived menaquinone-7. Blood 2007; 109: 3279-3283. DOI: 10.1182/blood-2006-08-040709.

7. Thijssen HHW, Drittij-Reijnders MJ. Vitamin K status in human tissues: tissue-specific accumulation of phylloquinone and menaquinone-4. Br J Nutr 1996;75: 121-127

8. Okano T, Shimomura Y, Yamane M, Suhara Y, Kamao $\mathrm{M}$, Sugiura $\mathrm{M}$, et al. Conversion of phylloquinone (Vitamin K1) into menaquinone-4 (Vitamin K2) in mice. J Biol Chem 2008; 283(17): 11270-11279. DOI: 10.1074/jbc.M702971200.
9. Card DJ, Gorska R, Cutler J, Harrington DJ. Vitamin K metabolism: current knowledge and future research. Mol Nutr Food Res 2014; 58(8):1590-1600. DOI: 10.1002/mnfr.201300683.

10. Nakagawa K, Hirota Y, Sawada N, Yuge N, Watanabe $\mathrm{M}$, Uchino $\mathrm{Y}$, et al. Identification of UBIAD1 as a novel human menaquinone-4 biosynthetic enzyme. Nature 2010; 468: 117-121. DOI:10.1038/nature09464.

11. Kresge N, Simoni RD, Hill RL. The finding that prothrombin contains $\gamma$-carboxyglutamic acid: the work of Johan Stenflo. J Biol Chem 2009; 284(18): e1.

12. Szulc P, Chapuy MC, Meunier PJ, Delmas PD. Serum undercarboxylated osteocalcin is a marker of the risk of hip fracture in elderly women. J Clin Invest 1993; 91: 1769-1774.

13. Mawatari T, Miura H, Higaki H, Moro-Oka T, Kurata $\mathrm{K}$, Murakami T, et al. Effect of vitamin K2 on threedimensional trabecular microarchitecture in ovariectomized rats. J Bone Miner Res 2000; 15(9): 1810-1817.

14. Kobayashi M, Hara K, Akiyama Y. Effects of vitamin $\mathrm{K} 2$ (menatetrenone) on calcium balance in ovariectomized rats. Jpn J Pharmacol 2002; 88(1): 55-61.

15. Iwamoto I, Kosha S, Fujino T, Nagata Y. Effects of vitamin $\mathrm{K} 2$ on bone of ovariectomized rats and on a rat osteoblastic cell line. Gynecol Obstet Invest 2002; 53(3): 144-148.

16. Iwamoto J, Yeh JK, Schmidt A, Rowley E, Stanfield L, Takeda T, et al. Raloxifene and vitamin K2 combine to improve the femoral neck strength of ovariectomized rats. Calcif Tissue Int 2005; 77(2): 119-126. DOI: 10.1007/s00223-004-0277-8.

17. Nagura N, Komatsu J, Iwase H, Hosoda H, Ohbayashi O, Nagaoka I, et al. Effects of the combination of vitamin $\mathrm{K}$ and teriparatide on the bone metabolism in ovariectomized rats. Biomed Rep 2015; 3(3): 295-300. DOI: $10.3892 /$ br.2015.431.

18. Huang Y. Combined treatment of vitamin $\mathrm{K}$ and teriparatide on bone metabolism and biomechanics in rats with osteoporosis. Exp Ther Med 2017; 15: 315-319. DOI: 10.3892/etm.2017.5420.

19. Yamaguchi M, Taguchi H, Gao YH, Igarashi A, Tsukamoto Y. Effect of vitamin K2 (menaquinone-7) in fermented soybean (natto) on bone loss in ovariectomized rats. J Bone Miner Metab 1999; 17(1): 23-29.

20. Fu X, Moreines J, Booth SL. Vitamin K supplementation does not prevent bone loss in ovariectomized Norway rats. Nutr Metab (Lond) 2012; 9(1): 12. DOI: 
10.1186/1743-7075-9-12.

21. Iwamoto J, Yeh JK, Takeda T. Effect of vitamin K2 on cortical and cancellous bones in orchidectomized and/ or sciatic neurectomized rats. J Bone Miner Res 2003; 18(4): 776-783.

22. Hara K, Kobayashi M, Akiyama Y. Vitamin K2 (menatetrenone) inhibits bone loss induced by prednisolone partly through enhancement of bone formation in rats. Bone 2002; 31(5): 575-581.

23. Iwamoto J, Seki A, Sato Y, Matsumoto H, Tadeda T, Yeh JK. Vitamin K2 promotes bone healing in a rat femoral osteotomy model with or without glucocorticoid treatment. Calcif Tissue Int 2010; 86(3): 234-241. DOI: 10.1007/s00223-010-9333-8.

24. Onodera K, Takahashi A, Sakurada S, Okano Y. Effects of phenytoin and/or vitamin K2 (menatetrenone) on bone mineral density in the tibiae of growing rats. Life Sci 2002; 70(13): 1533-1542.

25. Onodera K, Takahashi A, Wakabayashi H, Kamei J, Sakurada S. Effects of menatetrenone on the bone and serum levels of vitamin K2 (menaquinone derivatives) in osteopenia induced by phenytoin in growing rats. Nutrition 2003; 19(5): 446-450.

26. Feskanich D, Weber P, Willett WC, Rockett H, Booth SL, Colditz GA. Vitamin K intake and hip fractures in women: a prospective study. Am J Clin Nutr 1999; 69: 74-79.

27. Kaneki M, Hodges SJ, Hosoi T, Fujiwara S, Lyons A, Crean SJ, et al. Japanese fermented soybean food as the major determinant of the large geographic difference in circulating levels of vitamin K2: possible implications for hip-fracture risk. Nutrition 2001; 17(4): 315-321.

28. Yaegashi Y, Onoda T, Tanno K, Kuribayashi T, Sakata $\mathrm{K}$, Orimo $\mathrm{H}$. Association of hip fracture incidence and intake of calcium, magnesium, vitamin $\mathrm{D}$, and vitamin K. Eur J Epidemiol 2008; 23(3): 219-225. DOI: 10.1007/s10654-008-9225-7.

29. Booth SL, Tucker KL, Chen H, Hannan MT, Gagnon DR, Cupples LA, et al. Dietary vitamin K intakes are associated with hip fracture but not with bone mineral density in elderly men and women. Am J Clin Nutr 2000; 71(5): 1201-1208.

30. Apalset EM, Gjesdal CG, Eide GE, Tell GS. Intake of vitamin $\mathrm{K} 1$ and $\mathrm{K} 2$ and risk of hip fractures: The Hordaland Health Study. Bone 2011; 49(5): 990-995. DOI: 10.1016/j.bone.2011.07.035.

31. Ikeda Y, Iki M, Morita A, Kajita E, Kagamimori S,
Kagawa Y, et al. Intake of fermented soybeans, natto, is associated with reduced bone loss in postmenopausal women: Japanese Population-Based Osteoporosis (JPOS) Study. J Nutr 2006; 136(5): 1323-1328.

32. Macdonald HM, McGuigan FE, Lanham-New SA, Fraser WD, Ralston SH, Reid DM. Vitamin K1 intake is associated with higher bone mineral density and reduced bone resorption in early postmenopausal Scottish women: no evidence of gene-nutrient interaction with apolipoprotein E polymorphisms. Am J Clin Nutr 2008; 87(5): 1513-1520.

33. Rejnmark L, Vestergaard P, Charles P, Hermann AP, Brot $\mathrm{C}$, Eiken $\mathrm{P}$, et al. No effect of vitamin $\mathrm{K} 1$ intake on bone mineral density and fracture risk in perimenopausal women. Osteoporos Int 2006; 17(8): 1122-1132. DOI: 10.1007/s00198-005-0044-3.

34. McLean RR, Booth SL, Kiel DP, Broe KE, Gagnon DR, Tucker KL, et al. Association of dietary and biochemical measures of vitamin $\mathrm{K}$ with quantitative ultrasound of the heel in men and women. Osteoporos Int 2006; 17(4): 600-607. DOI: 10.1007/s00198-005-0022-9.

35. Fujita Y, Iki M, Tamaki J, Kouda K, Yura A, Kadowaki $\mathrm{E}$, et al. Association between vitamin $\mathrm{K}$ intake from fermented soybeans, natto, and bone mineral density in elderly Japanese men: the Fujiwara-kyo Osteoporosis Risk in Men (FORMEN) study. Osteoporos Int 2012; 23(2): 705-714. DOI: 10.1007/s00198-011-1594-1.

36. Hao G, Zhang B, Gu M, Chen C, Zhang Q, Zhang G, et $a l$. Vitamin $\mathrm{K}$ intake and the risk of fractures: A metaanalysis. Medicine (Baltimore) 2017; 96(17): e6725. DOI:10.1097/MD.0000000000006725.

37. Shiraki M, Shiraki Y, Aoki C, Miura M. Vitamin K2 (menatetrenone) effectively prevents fractures and sustains lumbar bone mineral density in osteoporosis. $J$ Bone Miner Res 2000; 15(3): 515-521.

38. Iwamoto J, Takeda T, Ichimura S. Effect of combined administration of vitamin D3 and vitamin K2 on bone mineral density of the lumbar spine in postmenopausal women with osteoporosis. J Orthop Sci 2000; 5(6): 546-551.

39. Ushiroyama T, Ikeda A, Ueki M. Effect of continuous combined therapy with vitamin $\mathrm{K}(2)$ and vitamin $\mathrm{D}(3)$ on bone mineral density and coagulofibrinolysis function in postmenopausal women. Maturitas 2002; 41(3): 211-221.

40. Cheung AM, Tile L, Lee Y, Tomlinson G, Hawker G, Scher J, et al. Vitamin K supplementation in postmeno- 
pausal women with osteopenia (ECKO trial): a randomized controlled trial. PLoS Med 2008; 5(10): e196. DOI: 10.1371/journal.pmed.0050196.

41. Booth SL, Dallal G, Shea MK, Gundberg C, Peterson JW, Dawson-Hughes B. Effect of vitamin K supplementation on bone loss in elderly men and women. $J$ Clin Endocrinol Metab 2008; 93(4): 1217-1223. DOI: 10.1210/jc.2007-2490.

42. Binkley N, Harke J, Krueger D, Engelke J, Vallarta-Ast $\mathrm{N}$, Gemar D, et al. Vitamin K treatment reduces undercarboxylated osteocalcin but does not alter bone turnover, density, or geometry in healthy postmenopausal North American women. J Bone Miner Res 2009; 24(6): 983-991. DOI: 10.1359/JBMR.081254.

43. Inoue $\mathrm{T}$, Fujita $\mathrm{T}$, Kishimoto H, Makino T, Nakamura T, Nakamura T, et al. Randomized controlled study on the prevention of osteoporotic fractures (OF study): a phase IV clinical study of 15-mg menatetrenone capsules. $J$ Bone Miner Metab 2009; 27(1): 66-75. DOI: 10.1007/ s00774-008-0008-8.

44. Emaus N, Gjesdal CG, Almas B, Christensen M, Grimsgaard AS, Berntsen GKR, et al. Vitamin K2 supplementation does not influence bone loss in early menopausal women: a randomised double-blind placebo-controlled trial. Osteoporos Int 2010; 21(10): 17311740. DOI 10.1007/s00198-009-1126-4.

45. Kanellakis S, Moschonis G, Tenta R, Schaafsma A, van den Heuvel EG, Papaioannou N, et al. Changes in parameters of bone metabolism in postmenopausal women following a 12-month intervention period using dairy products enriched with calcium, vitamin $\mathrm{D}$, and phylloquinone (vitamin $\mathrm{K}(1)$ ) or menaquinone-7 (vitamin $\mathrm{K}$ (2)): the Postmenopausal Health Study II. Calcif Tissue Int 2012; 90(4): 251-262. DOI: 10.1007/s00223-0129571-z.

46. Koitaya N, Sekiguchi M, Tousen Y, Nishide Y, Morita A, Yamauchi J, et al. Low-dose vitamin K2 (MK-4) supplementation for 12 months improves bone metabolism and prevents forearm bone loss in postmenopausal Japanese women. J Bone Miner Metab 2014; 32(2): 142-150. DOI: 10.1007/s00774-013-0472-7.

47. Cockayne S, Adamson J, Lanham-New S, Shearer MJ, Gilbody S, Torgerson DJ. Vitamin K and the prevention of fractures: systematic review and meta-analysis of randomized controlled trials. Arch Intern Med 2006; 166(12): 1256-1261.

48. Iwamoto J. Vitamin $\mathrm{K} \square$ therapy for postmenopausal osteoporosis. Nutrients 2014; 6(5): 1971-1980. DOI: 10.3390/nu6051971.

49. Guralp O, Erel CT. Effects of vitamin K in postmenopausal women: mini review. Maturitas 2014; 77(3): 294-299. DOI: 10.1016/j.maturitas.2013.11.002.

50. Caraballo PJ, Heit JA, Atkinson EJ, Silverstein MD, O'Fallon WM, Castro MR, et al. Long-term use of oral anticoagulants and the risk of fracture. Arch Intern Med 1999; 159(15):1750-1756.

51. Misra D, Zhang Y, Peloquin C, Choi HK, Kiel DP, Neogi T. Incident long-term warfarin use and risk of osteoporotic fractures: propensity-score matched cohort of elders with new onset atrial fibrillation. Osteoporos Int 2014; 25(6): 1677-1684. DOI: 10.1007/s00198-0142662-0.

52. Barnes $\mathrm{C}$, Newall $\mathrm{F}$, Ignjatovic $\mathrm{V}$, Wong $\mathrm{P}$, Cameron $\mathrm{F}$, Jones $\mathrm{G}$, et al. Reduced bone density in children on long-term warfarin. Pediatr Res 2005; 57(4): 578-581. DOI: 10.1203/01.PDR.0000155943.07244.04.

53. Fusaro M, Tripepi G, Noale M, Plebani M, Zaninotto M, Piccoli A, et al. Prevalence of vertebral fractures, vascular calcifications, and mortality in warfarin treated hemodialysis patients. Curr Vasc Pharmacol 2015; 13(2): 248-258. DOI: 10.2174/15701611113119990146.

54. Pauli RM. Mechanism of bone and cartilage maldevelopment in the warfarin embryopathy. Pathol Immunopathol Res 1988; 7(1-2): 107-112.

55. Ducy P, Desbois C, Boyce B, Pinero G, Story B, Dunstan $\mathrm{C}$, et al. Increased bone formation in osteocalcin-deficient mice. Nature 1996; 382(6590): 448-452.

56. Azuma K, Shiba S, Hasegawa T, Ikeda K, Urano T, Horie-Inoue $\mathrm{K}$, et al. Osteoblast-Specific $\gamma$-Glutamyl Carboxylase-Deficient Mice Display Enhanced Bone Formation With Aberrant Mineralization. J Bone Miner Res 2015; 30(7): 1245-1254. DOI: 10.1111/ggi.12060.

57. Boskey AL, Gadaleta S, Gundberg C, Doty SB, Ducy P, Karsenty G. Fourier transform infrared microspectroscopic analysis of bones of osteocalcin-deficient mice provides insight into the function of osteocalcin. Bone 1998; 23(3): 187-196.

58. Poundarik AA, Diab T, Sroga GE, Ural A, Boskey AL, Gundberg CM, et al. Dilatational band formation in bone. Proc Natl Acad Sci USA 2012; 109(47): 1917819183. DOI: $10.1073 /$ pnas.1201513109.

59. Luo G, Ducy P, McKee MD, Pinero GJ, Loyer E, Behringer RR, et al. Spontaneous calcification of arteries and cartilage in mice lacking matrix GLA protein. 
Nature 1997; 386(6620): 78-81.

60. Marulanda J, Gao C, Roman H, Henderson JE, Murshed M. Prevention of arterial calcification corrects the low bone mass phenotype in MGP-deficient mice. Bone 2013; 57(2): 499-508. DOI: 10.1016/j.bone.2013.08.021.

61. Bonnet N, Garnero P, Ferrari S. Periostin action in bone. Mol Cell Endocrinol 2016; 432: 75-82. DOI: 10.1016/j. mce.2015.12.014.

62. Zhu S, Barbe MF, Liu C, Hadjiargyrou M, Popoff SN, Rani S, et al. Periostin-like-factor in osteogenesis. $J$ Cell Physiol 2009; 218(3): 584-592. DOI: 10.1002/ jcp.21633.

63. Tabb MM, Sun A, Zhou C, Grün F, Errandi J, Romero $\mathrm{K}$, et al. Vitamin $\mathrm{K} 2$ regulation of bone homeostasis is mediated by the steroid and xenobiotic receptor SXR. $J$ Biol Chem 2003; 278(45): 43919-43927. DOI: 10.1074/ jbc.M303136200.

64. Horie-Inoue K, Inoue S. Steroid and xenobiotic receptor mediates a novel vitamin K2 signaling pathway in osteoblastic cells. J Bone Miner Metab 2008; 26(1): 9-12. DOI: 10.1007/s00774-007-0792-6.

65. Atkins GJ, Welldon KJ, Wijenayaka AR, Bonewald LF, Findlay DM. Vitamin K promotes mineralization, osteoblast-to-osteocyte transition, and an anticatabolic phenotype by \{gamma\}-carboxylation-dependent and -independent mechanisms. Am J Physiol Cell Physiol 2009; 297(6): C1358-1367. DOI:10.1152/ajpcell.00216.2009.

66. Ichikawa T, Horie-Inoue K, Ikeda K, Blumberg B, Inoue S. Vitamin K2 induces phosphorylation of protein kinase A and expression of novel target genes in osteoblastic cells. J Mol Endocrinol 2007; 39(4): 239-247. DOI: 10.1677/JME-07-0048.

67. Novack DV. Role of NF- $\mathrm{BB}$ in the skeleton. Cell Res 2011; 21: 169-182. DOI:10.1038/cr.2010.159.

68. Yamaguchi M, Weitzmann MN. Vitamin K2 stimulates osteoblastogenesis and suppresses osteoclastogenesis by suppressing NF- $\mathrm{KB}$ activation. Int $J$ Mol Med 2011; 27(1): 3-14. DOI: 10.3892/ijmm.2010.562.

69. Rubinacci A. Expanding the functional spectrum of vitamin $\mathrm{K}$ in bone. Focus on: "Vitamin $\mathrm{K}$ promotes mineralization, osteoblast to osteocyte transition, and an anticatabolic phenotype by \{gamma\}-carboxylation-dependent and -independent mechanisms". Am J Physiol Cell Physiol 2009; 297(6): C1336-1338. DOI:10.1152/ ajpcell.00452.2009.

70. Giachelli CM. Vascular calcification mechanisms. J Am Soc Nephrol 2004;15(12): 2959-2964. DOI:
10.1097/01.ASN.0000145894.57533.C4.

71. Mizobuchi M, Towler D, Slatopolsky E. Vascular calcification: the killer of patients with chronic kidney disease. J Am Soc Nephrol 2009; 20(7): 145 -164. DOI: 10.1681/ASN.2008070692.

72. Schurgers LJ. Vitamin K: key vitamin in controlling vascular calcification in chronic kidney disease. Kidney Int 2013; 83(5): 782-784. DOI: 10.1038/ki.2013.26.

73. Price PA, Urist MR, Otawara Y. Matrix Gla protein, a new gamma-carboxyglutamic acid-containing protein which is associated with the organic matrix of bone. Biochem Biophys Res Commun 1983; 117(3): 765-771.

74. Price PA, Faus SA, Williamson MK. Warfarin causes rapid calcification of the elastic lamellae in rat arteries and heart valves. Arterioscler Thromb Vasc Biol 1998; 18(9): 1400-1407.

75. Schurgers LJ, Spronk HM, Soute BA, Schiffers PM, DeMey JG, Vermeer C. Regression of warfarin-induced medial elastocalcinosis by high intake of vitamin $\mathrm{K}$ in rats. Blood 2007; 109(7): 2823-2831. DOI 10.1182/ blood-2006-07-035345.

76. Spronk HM, Soute BA, Schurgers LJ, Thijssen HH, De Mey JG, Vermeer C. Tissue-specific utilization of menaquinone-4 results in the prevention of arterial calcification in warfarin-treated rats. J Vasc Res 2003; 40: 531-537. DOI: 10.1159/000075344.

77. Schurgers LJ, Teunissen KJ, Knapen MH, Kwaijtaal M, van Diest R, Appels A, et al. Novel conformation-specific antibodies against matrix gamma-carboxyglutamic acid (Gla) protein: undercarboxylated matrix Gla protein as marker for vascular calcification. Arterioscler Thromb Vasc Biol 2005; 25(8): 1629-1633. DOI: 10.1161/01.ATV.0000173313.46222.43.

78. Schurgers LJ, Cranenburg EC, Vermeer C. Matrix Glaprotein: the calcification inhibitor in need of vitamin $\mathrm{K}$. Thromb Haemost 2008; 100(4): 593-603. DOI:10.1160/ TH08-02-0087.

79. Schurgers LJ, Spronk HM, Skepper JN, Hackeng TM, Shanahan CM, Vermeer C, et al. Post-translational modifications regulate matrix Gla protein function: importance for inhibition of vascular smooth muscle cell calcification. J Thromb Haemost 2007; 5(12): 2503 -2511. DOI: 10.1111/j.1538-7836.2007.02758.x.

80. Dalmeijer GW, van der Schouw YT, Magdeleyns EJ, Vermeer C, Verschuren WM, Boer JM, et al. Matrix Gla protein species and risk of cardiovascular events in type 2 diabetic patients. Diabetes Care 2013; 36(11):3766- 
3771. DOI: 10.2337/dc13-0065.

81. van den Heuvel EG, van Schoor NM, Lips P, Magdeleyns EJ, Deeg DJ, Vermeer C, et al. Circulating uncarboxylated matrix Gla protein, a marker of vitamin $\mathrm{K}$ status, as a risk factor of cardiovascular disease. Maturitas 2014; 77(2): 137-141. DOI: 10.1016/j.maturitas.2013.10.008.

82. Wallin R, Cain D, Hutson SM, Sane DC, Loeser R. Modulation of the binding of matrix Gla protein (MGP) to bone morphogenetic protein-2 (BMP-2). Thromb Haemost 2000; 84(6): 1039-1044.

83. Boström K, Tsao D, Shen S, Wang Y, Demer LL. Matrix GLA protein modulates differentiation induced by bone morphogenetic protein-2 in C3H10T1/2 cells. J Biol Chem 2001; 276(17): 14044-14052.

84. Proudfoot D, Shanahan CM. Molecular mechanisms mediating vascular calcification: role of matrix Gla protein. Nephrology (Carlton) 2006; 11(5): 455-461. DOI:10.1111/j.1440-1797.2006.00660.x.

85. Viegas CS, Simes DC, Laizé V, Williamson MK, Price PA, Cancela ML. Gla-rich protein (GRP), a new vitamin K-dependent protein identified from sturgeon cartilage and highly conserved in vertebrates. $J$ Biol Chem 2008; 283(52): 36655-36664. DOI: 10.1074/jbc. M802761200.

86. Eitzinger N, Surmann-Schmitt C, Bösl M, Schett G, Engelke K, Hess A, et al. Ucma is not necessary for normal development of the mouse skeleton. Bone 2012; 50(3): 670-680. DOI: 10.1016/j.bone.2011.11.017.

87. Neacsu CD, Grosch M, Tejada M, Winterpacht A, Paulsson M, Wagener R, et al. Ucmaa (Grp-2) is required for zebrafish skeletal development. Evidence for a functional role of its glutamate $\gamma$-carboxylation. Matrix Biol 2011; 30(7-8): 369-378. DOI:10.1016/j. matbio.2011.07.002.

88. Viegas CS, Cavaco S, Neves PL, Ferreira A, João A, Williamson MK, et al. Gla-rich protein is a novel vitamin $\mathrm{K}$-dependent protein present in serum that accumulates at sites of pathological calcifications. Am J Pathol 2009; 175(6): 2288-2298. DOI: 10.2353/ajpath.2009.090474.

89. Viegas CS, Rafael MS, Enriquez JL, Teixeira A, Vitorino R, Luís IM, et al. Gla-rich protein acts as a calcification inhibitor in the human cardiovascular system. Arterioscler Thromb Vasc Biol 2015; 35(2): 399-408. DOI: 10.1161/ATVBAHA.114.304823.

90. Viegas CS, Simes DC. Gla-rich protein (GRP): A new player in the burden of vascular calcification. $J$ Cardiovasc Dis Diagn 2016; 4: 245. DOI:10.4172/2329-
9517.1000245.

91. Fernández-Fernández L, Bellido-Martín L, García de Frutos P. Growth arrest-specific gene 6 (GAS6). An outline of its role in haemostasis and inflammation. Thromb Haemost 2008; 100(4): 604-610. DOI: 10.1160/TH0804-0253.

92. Lemke G. Biology of the TAM receptors. Cold Spring Harb Perspect Biol 2013; 5(11): a009076. DOI: 10.1101/cshperspect.a009076.

93. Qiu C, Zheng $\mathrm{H}$, Tao H, Yu W, Jiang X, Li A, et al. Vitamin K2 inhibits rat vascular smooth muscle cell calcification by restoring the Gas6/Axl/Akt anti-apoptotic pathway. Mol Cell Biochem 2017; DOI: 10.1007/ s11010-017-3023-z.

94. Geleijnse JM, Vermeer C, Grobbee DE, Schurgers LJ, Knapen MH, van der Meer IM, et al. Dietary intake of menaquinone is associated with a reduced risk of coronary heart disease: the Rotterdam Study. J Nutr 2004; 134(11): 3100-3105.

95. Shea MK, Holden RM. Vitamin K status and vascular calcification: evidence from observational and clinical studies. Adv Nutr 2012; 3(2): 158-165. DOI: 10.3945/ an.111.001644.

96. Shea MK, O’Donnell CJ, Hoffmann U, Dallal GE, Dawson-Hughes B, Ordovas JM, et al. Vitamin K supplementation and progression of coronary artery calcium in older men and women. Am J Clin Nutr 2009; 89(6): 1799-1807. DOI: 10.3945/ajcn.2008.27338.

97. Shea MK, Booth SL, Miller ME, Burke GL, Chen $\mathrm{H}$, Cushman $\mathrm{M}$, et al. Association between circulating vitamin $\mathrm{K} 1$ and coronary calcium progression in community-dwelling adults: the Multi-Ethnic Study of Atherosclerosis. Am J Clin Nutr 2013; 98(1): 197-208. DOI: 10.3945/ajcn.112.056101.

98. Dalmeijer GW, van der Schouw YT, Magdeleyns EJ, Vermeer C, Verschuren WM, Boer JM, et al. Circulating desphospho-uncarboxylated matrix $\gamma$-carboxyglutamate protein and the risk of coronary heart disease and stroke. J Thromb Haemost 2014; 12(7): 1028-1034. DOI: 10.1111/jth.12609.

99. Dalmeijer GW, van der Schouw YT, Magdeleyns EJ, Vermeer C, Elias SG, Velthuis BK, et al. Circulating species of matrix Gla protein and the risk of vascular calcification in healthy women. Int J Cardiol 2013; 168(6): 168-170. DOI: 10.1016/j.ijcard.2013.08.062.

100. van Popele NM, Mattace-Raso FU, Vliegenthart R, Grobbee DE, Asmar R, van der Kuip DA, et al. Aortic 
stiffness is associated with atherosclerosis of the coronary arteries in older adults: the Rotterdam Study. $J$ Hypertens 2006; 24(12): 2371-2376. DOI: 10.1097/01. hjh.0000251896.62873.c4.

101. Pivin E, Ponte B, Pruijm M, Ackermann D, Guessous I, Ehret G, et al. Inactive Matrix Gla-Protein Is Associated With Arterial Stiffness in an Adult Population-Based Study. Hypertension 2015; 66(1): 85-92. DOI: 10.1161/ HYPERTENSIONAHA.115.05177.

102. Mayer O Jr, Seidlerova J, Wohlfahrt P, Filipovsky J, Vanek J, Cifkova R, et al. Desphospho-uncarboxylated matrix Gla protein is associated with increased aortic stiffness in a general population. J Hum Hypertens 2016; 30(7): 418-423. DOI: 10.1038/jhh.2015.55.

103. Sardana M, Vasim I, Varakantam S, Kewan U, Tariq A, Koppula MR, et al. Inactive matrix Gla-protein and arterial stiffness in type 2 diabetes mellitus. Am J Hypertension 2017; 30(2):196-201. DOI: 10.1093/ajh/ hpw146.

104. Mayer O Jr, Seidlerova J, Bruthans J, Filipovsky J, Timoracka K, Vanek J, et al. Desphosphouncarboxylated matrix Gla-protein is associated with mortality risk in patients with chronic stable vascular disease. Atherosclerosis 2014; 235(1): 162-168. DOI: 10.1016/j.atherosclerosis.2014.04.027.

105. Holden RM, Morton AR, Garland JS, Pavlov A, Day AG, Booth SL. Vitamins K and D status in stages 3-5 chronic kidney disease. Clin J Am Soc Nephrol 2010; 5(4): 590-597. DOI: 10.2215/CJN.06420909.

106. Zhelyazkova-Savova M, Galunska B, Gerova D, Siderova M, Zorcheva R, PaskalevD. Undercarboxylated osteocalcin in postmenopausal patients on hemodialysis. Nephrology (St. Petersburg) 2011: 15(3): 35-39.

107. Keyzer CA, Vermeer C, Joosten MM, Knapen MH, Drummen NE, Navis G, et al. Vitamin K status and mortality after kidney transplantation: a cohort study. Am J Kidney Dis 2015; 65(3): 474-483. DOI: 10.1053/j. ajkd.2014.09.014.

108. Cranenburg EC, Brandenburg VM, Vermeer C, Stenger M, Mühlenbruch G, Mahnken AH, et al. Uncarboxylated matrix Gla protein (ucMGP) is associated with coronary artery calcification in haemodialysis patients. Thromb Haemost 2009; 101(2): 359-366.

109. Schlieper G, Westenfeld R, Krüger T, Cranenburg EC, Magdeleyns EJ, Brandenburg VM, et al. Circulating nonphosphorylated carboxylated matrix gla protein predicts survival in ESRD. J Am Soc Nephrol 2011; 22(2):
387-395. DOI: 10.1681/ASN.2010040339.

110. Westenfeld R, Krueger T, Schlieper G, Cranenburg EC, Magdeleyns EJ, Heidenreich S, et al. Effect of vitamin $\mathrm{K} 2$ supplementation on functional vitamin $\mathrm{K}$ deficiency in hemodialysis patients: a randomized trial. $\mathrm{Am} \mathrm{J}$ Kidney Dis 2012; 59(2): 186-195. DOI: 10.1053/j. ajkd.2011.10.041.

111. Knapen MH, Braam LA, Drummen NE, Bekers O, Hoeks AP, Vermeer C. Menaquinone-7 supplementation improves arterial stiffness in healthy postmenopausal women. A double-blind randomised clinical trial. Thromb Haemost 2015;113(5):1135-1144. DOI: 10.1160/TH14-08-0675.

112. Kurnatowska I, Grzelak P, Masajtis-Zagajewska A, Kaczmarska M, Stefańczyk L, Vermeer C, et al. Effect of vitamin $\mathrm{K} 2$ on progression of atherosclerosis and vascular calcification in nondialyzed patients with chronic kidney disease stages 3-5. Pol Arch Med Wewn. 2015; 125(9): 631-640.

113. Schurgers LJ, Aebert H, Vermeer C, Bültmann B, Janzen J. Oral anticoagulant treatment: friend or foe in cardiovascular disease? Blood 2004; 104(10): 3231-3232. DOI: 10.1182/blood-2004-04-1277.

114. Koos R, Mahnken AH, Mühlenbruch G, Brandenburg $\mathrm{V}$, Pflueger B, Wildberger JE, et al. Relation of oral anticoagulation to cardiac valvular and coronary calcium assessed by multislice spiral computed tomography. Am J Cardiol 2005; 96(6): 747-749. DOI: 10.1016/j.amjcard.2005.05.014.

115. Weijs B, Blaauw Y, Rennenberg RJ, Schurgers LJ, Timmermans CC, Pison L, et al. Patients using vitamin $\mathrm{K}$ antagonists show increased levels of coronary calcification: an observational study in low-risk atrial fibrillation patients. Eur Heart $J$ 2011; 32(20): 2555-2562. DOI: 10.1093/eurheartj/ehr226.

116. Andrews J, Psaltis PJ, Bayturan O, Shao M, Stegman B, Elshazly M, et al. Warfarin use is associated with progressive coronary arterial calcification: Insights from serial intravascular ultrasound. JACC Cardiovasc Imaging 2017; in press; DOI: 10.1016/j.jcmg.2017.04.010.

117. Rennenberg RJ, van Varik BJ, Schurgers LJ, Hamulyak $\mathrm{K}$, Ten Cate H, Leiner T, et al. Chronic coumarin treatment is associated with increased extracoronary arterial calcification in humans. Blood 2010; 115(24): 51215123. DOI: 10.1182/blood-2010-01-264598.

118. Tantisattamo E, Han KH, O'Neill WC. Increased vascular calcification in patients receiving warfarin. 
Arterioscler Thromb Vasc Biol 2015; 35(1): 237-242. DOI: 10.1161/ATVBAHA.114.304392.

119. Han KH, O'Neill WC. Increased peripheral arterial calcification in patients receiving warfarin. $J$ Am Heart Assoc 2016; 5(1). DOI: 10.1161/JAHA.115.002665.

120. Alvarez-Pérez A, Gutiérrez-González E, SánchezAguilar D, Toribio J. Atypical calciphylaxis secondary to treatment with acenocoumarol. Actas Dermosifiliogr 2012; 103(1): 79-81. DOI: 10.1016/j. adeng1.2011.01.006.

121. Nour SA, Nour HA, Mehta J, Roy T, Byrd R. Tracheobronchial calcification due to warfarin therapy. Am J Respir Crit Care Med 2014; 189(12): e73. DOI: 10.1164/rccm.201305-0975IM.

122. Holden RM, Sanfilippo AS, Hopman WM, Zimmerman D, Garland JS, Morton AR. Warfarin and aortic valve calcification in hemodialysis patients. J Nephrol 2007; 20(4): 417-422.

123. Delanaye P, Krzesinski JM, Warling X, Moonen M, Smelten N, Médart L, et al. Dephosphorylateduncarboxylated Matrix Gla protein concentration is predictive of vitamin $\mathrm{K}$ status and is correlated with vascular calcification in a cohort of hemodialysis patients. BMC Nephrol 2014;15:145. DOI: 10.1186/1471-236915-145.

124. Lutz J, Jurk K, Schinzel H. Direct oral anticoagulants in patients with chronic kidney disease: patient selection and special considerations. Int $J$ Nephrol Renovasc Dis 2017; 10: 135-143. DOI: 10.2147/IJNRD.S105771.
125. McFarlane SI, Muniyappa R, Shin JJ, Bahtiyar G, Sowers JR. Osteoporosis and cardiovascular disease: brittle bones and boned arteries, is there a link? Endocrine 2004; 23(1): 1-10. DOI: 10.1385/ENDO:23:1:01.

126. London GM. Bone-vascular cross-talk. J Nephrol 2012; 25(5): 619-625. DOI: 10.5301/jn.5000187.

127. Flore R, Ponziani FR, Di Rienzo TA, Zocco MA, Flex A, Gerardino L, et al. Something more to say about calcium homeostasis: the role of vitamin K2 in vascular calcification and osteoporosis. Eur Rev Med Pharmacol Sci 2013; 17(18): 2433-2440.

128. Persy V, D'Haese P. Vascular calcification and bone disease: the calcification paradox. Trends Mol Med 2009; 15(9): 405-416. DOI: 10.1016/j.molmed.2009.07.001.

129. Bolland MJ, Barber PA, Doughty RN, Mason B, Horne A, Ames R, et al. Vascular events in healthy older women receiving calcium supplementation: randomised controlled trial. $B M J$ 2008; 336(7638): 262-266. DOI: 10.1136/bmj.39440.525752.

130. Caluwe R, Pyfferoen L, De Boeck K, De Vriese AS. The effects of vitamin $K$ supplementation and vitamin $K$ antagonists on progression of vascular calcification: ongoing randomized controlled trials. Clin Kidney $J$ 2016; 9(2): 273-279. DOI: 10.1093/ckj/sfv146.

131. Brandenburg VM, Schurgers LJ, Kaesler N, Püsche K, van Gorp RH, Leftheriotis G, et al. Prevention of vasculopathy by vitamin $\mathrm{K}$ supplementation: can we turn fiction into fact? Atherosclerosis 2015; 240(1): 10-16. DOI: $10.1016 /$ j.atherosclerosis.2015.02.040. 